San Jose State University

SJSU ScholarWorks

Faculty Publications

Psychology

November 1998

\title{
Ubiquitous molecular substrates for associative learning and activity-dependent neuronal facilitation.
}

\author{
Louis D. Matzel \\ Rutgers University - New Brunswick/Piscataway \\ Andrew C. Talk \\ Rutgers University - New Brunswick/Piscataway \\ Isabel A. Muzzio \\ University of Pennsylvania, imimuzzio@sas.upenn.edu \\ Ronald F. Rogers \\ San Jose State University, ronald.rogers@sjsu.edu
}

Follow this and additional works at: https://scholarworks.sjsu.edu/psych_pub

Part of the Psychology Commons

\section{Recommended Citation}

Louis D. Matzel, Andrew C. Talk, Isabel A. Muzzio, and Ronald F. Rogers. "Ubiquitous molecular substrates for associative learning and activity-dependent neuronal facilitation." Reviews in Neuroscience (1998): 129-167.

This Article is brought to you for free and open access by the Psychology at SJSU ScholarWorks. It has been accepted for inclusion in Faculty Publications by an authorized administrator of SJSU ScholarWorks. For more information, please contact scholarworks@sjsu.edu. 


\title{
Ubiquitous Molecular Substrates for Associative Learning and Activity-Dependent Neuronal Facilitation
}

\author{
Louis D. Matzel, Andrew C. Talk, Isabel A. Muzzio, and Ronald F. Rogers 1 \\ Department of Psychology, Program in Biopsychology and Behavioral Neuroscience \\ Rutgers University, New Brunswick NJ 08854-8020 \\ ${ }^{1}$ Department of Psychology, Program in Neural Science \\ Indiana University, Bloomington Indiana 47405, USA
}

\section{CONTENTS}

\section{Introduction}

2. Learning in Aplysia

2.1. Behavioral processes underlying associative learning

2.2. Network interactions underlying sensitization and associative learning

2.3. Induction of presynaptic facilitation during sensitization training

2.4. Stimulus convergence underlying associative learning in Aplysia

\section{Learning in Hermissenda}

3.1. Behavioral processes underlying associative learning

3.2. Network interactions underlying associative learning

3.3. Stimulus convergence and learning-induced neuronal facilitation

\section{Hippocampal long-term potentiation (LTP)}

4.1. Postsynaptic $\mathrm{Ca}^{2+}$ and LTP induction

4.2. $\mathrm{Ca}^{2+}$-dependent biochemical processes underlying LTP

4.3. Stimulus convergence and LTP induction

4.4. Multiple roles of PKC in LTP

4.5. Biophysical mechanisms of LTP expression

5. Ubiquitous mechanisms of activity-dependent facilitation

5.1. Network interactions necessary for the induction of facilitation

5.2. Biochemical and molecular constituents of facilitation

\section{Conclusion and summary of ubiquitous mechanisms}

\section{References}

\section{Reprint address:}

Louis D. Matzel

Department of Psychology

Program in Biopsychology and Behavioral Neuroscience

Rutgers University, Busch Campus

Piscataway, NJ 08854-8020, USA 


\section{SYNOPSIS}

Recent evidence suggests that many of the molecular cascades and substrates that contribute to learning-related forms of neuronal plasticity may be conserved across ostensibly disparate model systems. Notably, the facilitation of neuronal excitability and synaptic transmission that contribute to associative learning in Aplysia and Hermissenda, as well as associative LTP in hippocampal CA1 cells, all require (or are enhanced by) the convergence of a transient elevation in intracellular $\mathrm{Ca}^{2+}$ with transmitter binding to metabotropic cell-surface receptors. This temporal convergence of $\mathrm{Ca}^{2+}$ and G-protein-stimulated second-messenger cascades synergistically stimulates several classes of serine/threonine protein kinases, which in turn modulate receptor function or cell excitability through the phosphorylation of ion channels. We present a summary of the biophysical and molecular constituents of neuronal and synaptic facilitation in each of these three model systems. Although specific components of the underlying molecular cascades differ across these three systems, fundamental aspects of these cascades are widely conserved, leading to the conclusion that the conceptual semblance of these superficially disparate systems is far greater than is generally acknowledged. We suggest that the elucidation of mechanistic similarities between different systems will ultimately fulfill the goal of

\footnotetext{
Abbreviations: AA (arachidonic acic); ACPD (aminocyclopentane-1S,3R-dicarboxylic acid); $\mathrm{AlF}_{4}^{-}$(aluminum/ fluoride complex); AMPA ( $\alpha$-amino-3-hydroxy-5-methyl-4isoxazolepropionate); ATP (adenosine 5'-triphosphate); CaMK (calcium/calmodulin-dependent protein kinase); CS (conditioned stimulus); DAG (diacylglycerol); EPSP (excitatory postsynaptic potential); ER (endoplasmic reticculum); GABA ( $\gamma$-amino-n-butyric acid); G-protein (guanosine 5'triphosphate-binding protein); GDP (trilithium salt of guanosine); GTP (tetralithium salt of guanosine); I (ion current); $\quad \mathrm{IP}_{3}$ (inositol trisphosphate); LTP (long-term potentiation); mGluR (metabotropic glutamate receptor); NMDA (N-methyl-D-aspartate); PLC (phospholipase C); PLA2 (phospholipase $\mathrm{A}_{2}$ ); $\mathrm{PIP}_{2}$ (phosphatidylinositol-4,5bisphosphate); PKA (cyclic AMP-dependent kinase); PKC (protein kinase C); TEA (tetraethylammonium chloride); UFA (cis unsaturated fatty acid); US (unconditioned stimulus); 5-HT (5-hydroxytryptamine; serotonin).
}

the model systems approach, that is, the description of critical and ubiquitous features of neuronal and synaptic events that contribute to memory induction.

\section{KEY WORDS}

activity-dependent facilitation, calcium, protein kinases, metabotropic receptors, phospholipases, ionotropic receptors, Aplysia, Hermissenda, longterm potentiation, memory

\section{INTRODUCTION}

Prior to 1965, empirical insights pertaining to the mechanisms by which brain cells might encode new memories were infrequent. Progress was slowed in part by the complexity and technical difficulties associated with studies of the mammalian brain. In 1965, however, a pair of seminal papers by Eric Kandel and Ladisav Tauc /137,138/ appeared that addressed the neurophysiological basis for a learned response in the marine mollusc Aplysia, the relatively "simple" nervous system of which is comprised of identifiable cells. In this early work, Kandel and Tauc reported that synaptic facilitation of a weak pathway developed as a consequence of repeated stimulation of that pathway concomitant with the stimulation of a stronger afferent input. Furthermore, Kandel and Tauc reported that this "heterosynaptic facilitation" was mediated by an increase in presynaptic transmitter release. Not only did these early papers provide a conceptual basis for understanding brain mechanisms of memory, but perhaps more importantly, they served as the impetus for a major redirection of effort in the field of neuroscience. Since the original description of their results, literally thousands of papers have helped to delineate the mechanisms by which this and other forms of synaptic facilitation occur in Aplysia as well as in other "simple" systems. Through this body of work, it has become more fully appreciated that mechanisms of memory storage might be discernible if simple forms of learning were studied in species with tractable nervous systems. Moreover, this paradigm foreshadowed similar approaches which utilize reduced preparations of mammalian brains. 
The introduction of the "model systems" approach by Kandel and Tauc motivated a proliferation of invertebrate models (for reviews, see $/ 51,56,99,146 /)$, and has been applied in a similar fashion to vertebrate systems $/ 153,177 /$, although in the latter case without the benefits afforded by the ability to identify single cells. This proliferation is in part attributable to the recognition that basic principles of cell biology, e.g., biophysical, biochemical, and molecular determinants of neuronal activity and transmission, are widely conserved across species and cell types. By implication, key elements of neuronal plasticity elucidated in simpler nervous systems or other reduced preparations might be conserved into the mammalian brain, and likewise, from simpler mammalian brains to humans. Support for this assumption would of course be strengthened to the extent that a similar conservation was found across various invertebrate systems. To some degree, the promise suggested by this approach has been slow to materialize. Many reviews of the model systems literature have suggested that common mechanisms underlying memory induction had not emerged, suggesting the unappealing possibility that the study of memory in these model systems might provide little insight into ubiquitous cellular properties of learning (but see $151,66,128,146 /)$. In the present article, we review a body of evidence which suggests that any such conclusion may have been premature. At the time of many earlier treatments of this subject, specific details of the mechanisms underlying learning in species other than Aplysia were somewhat sparse. In the case of Hermissenda, the mechanisms of learning appeared in some respects different from those described in Aplysia, and in other respects even antithetical $/ 17,56 /$. In contrast to these earlier disparities, recent evidence suggests that learning in Hermissenda may share many of the molecular constituents employed by Aplysia. Moreover, the recent elucidation of the contribution of the metabotropic glutamate receptor to some forms of longterm potentiation (LTP) in the mammalian brain suggests potential points of convergence between LTP and the forms of plasticity previously found to contribute to learning in invertebrates.

In the present review, we describe the behavioral processes and synaptic interactions within neural networks that underlie the induction of associative learning in Aplysia and Hermissenda, followed by a summary of the neurophysiological and molecular constituents of that learning. These learning-related forms of neuronal plasticity in the invertebrate nervous systems will be briefly compared to a prominent form of hippocampal LTP that has been suggested to contribute to some aspects of memory formation. We believe that these ostensibly disparate systems share many important and fundamental similarities, even though particular molecular constituents differ. Since learninginduced neuronal modifications are sure to be widespread throughout any nervous system, we suggest that many of the specific differences observed across preparations are not necessarily indicative of a lack of generality between species, but rather, reflect the diversity within the nervous system itself. It is our view that it is the ubiquitous features of learning-related neuronal modifications that are derived from these interspecies comparisons which are most likely to advance an understanding of the necessary and sufficient cellular constituents of memory.

The present review is limited primarily to mechanisms underlying memory induction, with only an occasional passing reference to long-term storage. This approach is necessary both for reasons of economy and because less is known (particularly in the cases of Hermissenda and LTP) regarding the maintenance of memory beyond the parameters imposed by normal protein degradation and turnover. Moreover, our principal concern will be with associative forms of learning, in which the response to a stimulus (referred to as a conditioned stimulus, or $\mathrm{CS}$ ) is modified as a result of its predictive relationship with some other stimulus of (usually) strong affective valence (referred to as an unconditioned stimulus, or US). This focus on associative learning is predicated on its pervasiveness among both simple and complex organisms, because the behavioral processes that govern the acquisition and expression of associatively conditioned responses are widely conserved among organisms with seemingly little else in common, and because it is thought to be a primary element of more complex forms of learning /265/. 


\section{LEARNING IN APL YSIA}

Since Aplysia is the prototypic (and the most fully developed) model system employed in the search for cellular memory mechanisms, we begin with a review of this preparation. We intentionally describe only the most critical features of this system as more extensive descriptions have been presented elsewhere (e.g., $/ 51,54,128,135 /$ ).

\subsection{Behavioral processes underlying associative learning in Aplysia californica}

Stimulated by the early examples of heterosynaptic facilitation in neurons of the abdominal ganglion $/ 137 /$, the marine mollusc Aplysia californica has enjoyed an extensive history of analysis directed at both associative and nonassociative forms of learning. Although our focus here is on the cellular and molecular substrates of associative conditioning, associative and nonassociative forms of learning may share common mechanisms in Aplysia $/ 124 /$, and this continuity between the processes and mechanisms will become apparent in the following pages.

While behavioral studies have demonstrated the capacity of Aplysia to learn a large repertoire of associations (e.g., $/ 71,158,258,267,268 /$ ), most investigations of associative learning in this animal have been directed at the acquisition of defensive withdrawal reflexes. Studies of associative learning in Aplysia have primarily focused on two simple defensive reflexes: gill/siphon withdrawal and tail withdrawal. In the experimentally naive Aplysia, application of a weak tactile stimulus to the siphon (CS) produces only a small withdrawal of the siphon and gill organs, while a brief electric shock (US) to the animal's tail results in a vigorous and more sustained withdrawal of both the siphon and gill. Carew, Walters, and Kandel /57/ found that as few as 15 temporally paired presentations of the CS and US were sufficient to induce a long-lasting (several days) conditioned siphon and gill withdrawal reflex that was expressed as both an increase in amplitude and persistence of the response to the $\mathrm{CS}$ alone. Consistent with an underlying associative process, random or unpaired presentations of the CS and US produced comparatively small changes in the animal's responses to the CS, although US presentations alone did result in a small enhancement of the withdrawal reflex which was attributable to nonassociative sensitization. This work was extended with the demonstration that the gill withdrawal reflex could be differentially conditioned using a light touch to the siphon (CS+) or mantle (CS-) as discriminative stimuli 155/. In this procedure the $\mathrm{CS}+$ is always presented contiguously with the US (tail shock), while the CS- is presented in isolation such that the animal's experience with the two CSs differs only in their temporal relationship with the US. Using this well balanced procedure and optimal training parameters, evidence of learning and 24 hour retention could be observed with as little as one conditioning trial. Furthermore, this form of conditioning seems analogous to vertebrate learning in that differential conditioning in Aplysia is degraded by backward or simultaneous CS and US presentations, and is sensitive to interstimulus interval and reduced CSUS contingency $165,125 /$.

\subsection{Network interactions underlying sensitization and associative learning in Aplysia}

It is an appealing feature of an invertebrate model system when some concordance of the processes underlying learning are observed between that system and its vertebrate counterparts. Although this phylogenetic conservation is interesting in itself (and in this case underscores the fundamental import of associative learning), the ultimate goal of this approach is to account for these processes at a neuronal level of analysis. To that end, cellular networks of sensory, interneuronal and motor cells that transduce CS and US information in Aplysia have been identified, and an overview of this network is presented in Figure 1. Tactile stimulation of the siphon or mantle excites the afferent terminals of mechanoreceptors whose cell bodies are found within the abdominal ganglion 153/. These sensory cells then synapse with excitatory projections onto motor neurons and interneurons also located in the abdominal ganglion /149/. Gill and siphon contractions arise from excitatory monosynaptic and polysynaptic input, respectively, from abdominal ganglion motor neurons. Tail shock (US) results in the stimulation of interneurons that synapse onto sensory neuron 
(siphon or mantle) terminals that are integral to the CS (siphon or mantle touch) pathways /136/. It is the innervation of the sensory neurons by the "facilitatory" interneurons that is critical to both nonassociative (US-induced sensitization) and associative modifications of the CS pathway.

\subsection{Induction of presynaptic facilitation during sensitization training}

As described, associative learning in Aplysia is at least in part attributable to an amplification of the sensitizing response to the US alone. In Aplysia, the small withdrawal of the gill induced by touch to the siphon is greatly enhanced if the animal had recently been exposed to a noxious stimulus such as tail shock $1217 /$, and in vitro preparations that permit the direct conditioning of identified neural pathways in the isolated abdominal ganglion have been instrumental in elucidating the cellular basis of this learned response. Sensitization in this reduced preparation is accompanied by an enhancement of the EPSP in a monosynaptic pathway between siphon sensory neurons and postsynaptic motor neurons mediating gill withdrawal, and this enhancement has been attributed to a presynaptic alteration in transmitter release $/ 58 /$.

As depicted in Figure 1, sensory information from the tail interacts with the siphon sensory neurons via a polysynaptic serotonergic $(5-\mathrm{HT})$ pathway $/ 126,127,166 /$. The mechanism of enhanced transmitter release in the siphon sensory neuron has its origin in two parallel 5-HT-induced second messenger cascades that culminate in the stimulation of a cAMP-dependent protein kinase (PKA) and $\mathrm{Ca}^{2+} /$ phospholipid-dependent protein kinase (PKC) /46/. The stimulation of PKA and PKC influences transmitter release in three general ways. These include: 1) the broadening of the action potential; 2) modulation of L-type $\mathrm{Ca}^{2+}$ currents, and 3) transmitter vesicle mobilization.

Surface receptors for 5-HT interact with at least two G-proteins: $G_{S}$, which is coupled to the cAMP pathway, and $\mathrm{G}_{\mathrm{o}}$, which is coupled to a parallel PKC pathway. $G_{S}$ stimulates the membrane bound enzyme, adenylate cyclase, which catalyzes the formation of CAMP from ATP. The newly formed cAMP binds the regulatory subunits of the cAMPdependent protein kinase (PKA), causing the

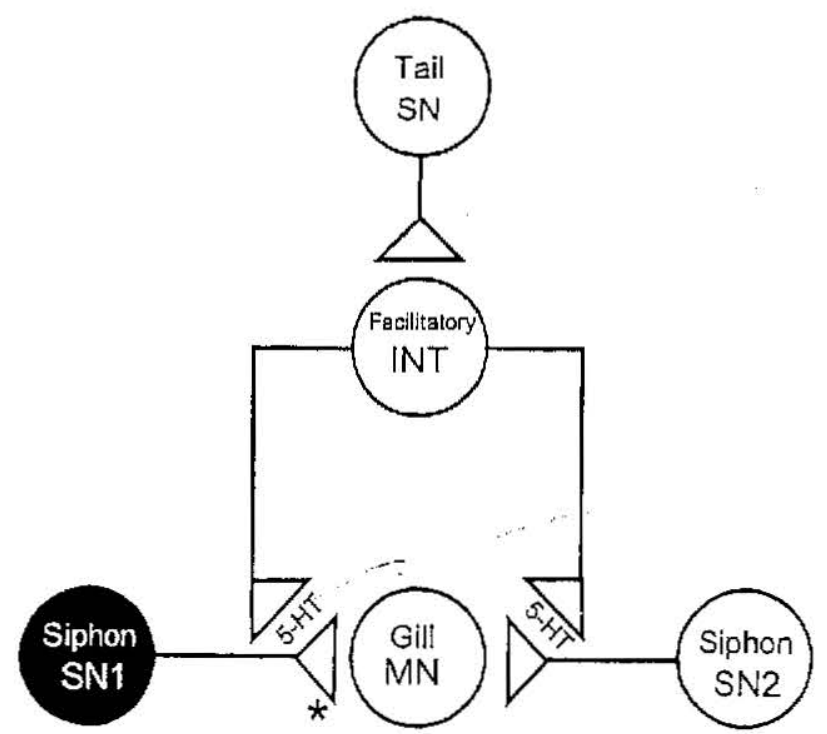

Fig. 1: A simplified depiction of the neural network that underlies associative leaming in Aplysia. During associative learning, a light touch to the siphon (CS) in the area innervated by siphon sensory neuron 1 (SN1) depolarizes that cell and normally induces a weak gill-withdrawal reflex via monosynaptic projections to gill motor neurons $(\mathrm{MN})$. Approximately $0.5 \mathrm{sec}$ after the siphon touch, a tail shock (US) is presented that stimulates tail sensory neurons which project via intemeurons onto siphon sensory cell axons. The binding of 5-HT to the SNI during a period of depolarization-induced activity modifies the cell in such a way that its synaptic interaction with gill motor neurons $(\mathrm{MN})$ is facilitated (*), inducing an enhanced gill withdrawl in response to the CS alone. Note that in the absence of conjoint transmitter binding and activity, the synaptic interaction between SN2 and the gill $\mathrm{MN}$ does not undergo facilitation beyond what may be caused by 5-HT alone (i.e, sensitization).

regulatory subunits of the enzyme to dissociate from the catalytic subunits. $G_{0}$ stimulates the activity of phospholipase C (PLC), which catalyzes the breakdown of membrane phospholipids into inositol trisphosphate $\left(\mathrm{IP}_{3}\right)$ and diacylglycerol (DAG). $\mathrm{IP}_{3}$ induced release of $\mathrm{Ca}^{2+}$ from cytosolic storage pools in combination with DAG induces the translocation of PKC from the cytosol to the membrane of the sensory cell $1233,251 /$. Upon translocation, PKC phosphorylates membrane proteins associated with voltage-dependent $\mathrm{K}^{+}$channels, reducing conduct- 
ance through these channels $/ 73 /$ and further prolonging action potential duration $1257 \%$. Thus, 5HT-induced activation of PKC is also associated with the movement of transmitter vesicles to the releasable pool, increasing the transmitter available for release $/ 112$ /.

5-HT has been reported to phosphorylate two specific classes of $\mathrm{K}^{+}$channels, the S-type $\mathrm{K}^{+}$ channels $\left(I_{K S}\right) / 144,246 /$ and the transient voltagedependent channel $\left(I_{K V}\right)$ 133,12\% . Reduction of these repolarizing currents ( $I_{K S}$ and $I_{K V}$ ) has been implicated in the broadening of action potentials, although their relative contributions are different. While $\mathrm{I}_{\mathrm{KV}}$ plays a prominent role in spike broadening, $\mathrm{I}_{\mathrm{KS}}$ is more important for regulating other measures of cell excitability $134,52 /$. Moreover, spike broadening is mediated by both PKC and PKA /257/ whereas increases in evoked spike rate or input resistance appear to be mediated primarily by PKA / 12, 145/.

One consequence of the prolonged depolarizing phase of the sensory cell's action potential following sensitization training is an enhancement of voltagedependent influx of $\mathrm{Ca}^{2+}$ through $\mathrm{N}$-type $\mathrm{Ca}^{2+}$ channels 190/. This potentiated elevation of intracellular $\mathrm{Ca}^{2+}$ appears to account for a large portion of the training-induced facilitation of the EPSP owing to the direct relationship between intracellular $\mathrm{Ca}^{2+}$ levels and presynaptic transmitter release. Additionally, Edmonds et al. /90/ report that 5-HT (or CAMP) application leads to a direct increase in conductance through the L-type $\mathrm{Ca}^{2+}$ channel (as opposed to a secondary effect as a result of decreased outward $\mathrm{K}^{+}$flux), presumably further increasing the availability of transmitter vesicles for release. The transduction pathway underlying this direct enhancement of $\mathrm{Ca}^{2+}$ conductance has not been elucidated, and we will not address it further here. In summary, the synaptic enhancement observed following sensitization training is the direct result of a protein kinase mediated increase in the availability of transmitter vesicles for release as well as a reduction of several classes of $\mathrm{K}^{+}$channels which facilitate that release.

\subsection{Stimulus convergence underlying associative learning in Aplysia}

Given the similarities between sensitization training and classical conditioning in Aplysia, initial studies of associative forms of learning in Aplysia were guided by the hypothesis that the mechanism underlying the induction of associative learning may be similar to, or an amplification of, nonassociative presynaptic facilitation. As such, the convergence of signals originating in the $C S$ and US sensory pathways might serve to amplify and prolong the synaptic facilitation that accompanies sensitization $164,137 /$. Support for this hypothesis was reported using differential classical conditioning of siphon sensory neurons /124/, and independently with a similar procedure in which tail sensory neuron stimulation served as the CS $1266 /$. In the partially intact preparation described above, Hawkins et al. /124/ performed a differential conditioning experiment in which CS+ and CS- stimuli consisted of current-evoked spike activity in two individual siphon sensory neurons. This in vitro conditioning arrangement can be discerned from Figure 1 . Stimulation of the CS+ pathway (depicted as the darkened sensory neuron in Figure 1) immediately preceded electrical shock to the tail (US), while stimulation of the CS- neuron was explicitly unpaired with US presentation. Conditioning was measured as a change in the magnitude of excitatory postsynaptic potentials (EPSPs) recorded from a common motor neuron (either siphon or gill motor neuron) efferent to both the CS+ and CS- sensory neurons. Under these conditions a moderate facilitation of the EPSP was recorded for both sensory neurons (as would arise from sensitization training). However, if the US (shock) was preceded by spike activity in the sensory neuron, as in the CS+ condition, the magnitude of this facilitation was significantly enhanced (and its maintenance prolonged) relative to the sensory cells that had received unpaired (CS-) training. Additional work with this in vitro preparation investigated the temporal constraints on effective CS-US interstimulus intervals, and found them to be in close agreement with the behavioral data previously described /64/. Two conclusions are immediately apparent based on these results as well as the similar results of Walters and Byrne. First, these bio- 
physical data are consistent with behavioral studies that indicate a requirement for temporal contiguity between a CS and US for efficient learning. This is evident in the finding that associative modifications are restricted to sensory pathways whose neuronal activities were correlated in time. In addition, the ability to differentially condition two pathways converging onto a common postsynaptic motor neuron indicates that the pairing-specific amplification of the EPSP must originate presynaptically, i.e., in the sensory neuron.

Consistent with a presynaptic locus of modulation, Hawkins et al. /124/ observed a pairingspecific increase in the duration of action potentials in the sensory neuron following differential conditioning in the reduced preparation. This broadening of the action potential was attributable in part to a reduction of conductance through $\mathrm{K}^{+}$ channels that resemble the $\mathrm{S}$ type- $\mathrm{K}^{+}$channel known to play a causal role in nonassociative presynaptic facilitation (cf. /143/). Moreover, it was reported that the spike-broadening normally induced by $5-\mathrm{HT}$ (i.e., as in sensitization) was significantly enhanced if its application was paired with a burst of activity in the sensory neuron $/ 106 /$. These data suggest that 5-HT is playing a modulatory role during associative learning similar to its role in sensitization, and that this modulatory action of 5-HT may be enhanced by contiguous activity in the sensory neuron.

The results described above indicate that the contribution of the US during associative learning in Aplysia is accounted for by the release of $5-\mathrm{HT}$ onto the sensory neuron, raising the question as to how the CS (spike activity) induces an enhancement of the 5-HT-dependent mechanism. Several converging lines of evidence have implicated an interaction between a CS-induced elevation in intracellular $\mathrm{Ca}^{2+}$ and 5-HT's stimulation of second messenger systems. First, the enhanced spikebroadening induced by the combined effects of 5HT and activity was found to be dependent on the presence of external $\mathrm{Ca}^{2+} / 2 /$. Furthermore, 5-HT, which is known to elevate cAMP levels in the sensory cell $/ 35 /$, induces a greater elevation if its application is closely preceded by spike activity in the sensory neuron /45/ (see also /208/). These findings suggest that the transmitter-induced elevation of intracellular cAMP levels might be amplified by a contiguous rise in intracellular $\mathrm{Ca}^{2+}$ during a train of spike activity. Previous work had demonstrated that adenylate cyclase, the enzyme responsible for CAMP production, possessed certain characteristics that made it attractive as a point of convergence between these two sensory signals /271/ and may be modulated in a $\mathrm{Ca}^{2+}$-dependent manner. This was confirmed with the observation that adenylate cyclase was stimulated by $\mathrm{Ca}^{2+} /$ calmodulin 192/, and that the cyclase was activated by physiologically relevant rates of firing $1279 /$. Furthermore, the same cyclase molecules that are modulated by $\mathrm{Ca}^{2+} /$ calmodulin also exhibit an increase in activity as a result of the 5-HT-induced stimulation of the G-protein-coupled receptor that mediates the US pathway $13 /$. Consequently, it can be surmised that both $\mathrm{Ca}^{2+}$ and 5-HT converge at the point of the sensory cell to synergistically activate adenylate cyclase during the in vitro conditioning procedure. Relevant to a role for this mechanism in associative conditioning, the synergistic activation of the cyclase by $\mathrm{Ca}^{2+}$ and 5-HT is most efficient when the $\mathrm{Ca}^{2+}$ signal generated by stimulation of the sensory neuron (i.e., the CS) precedes 5 -HT binding by roughly $500 \mathrm{~ms}$. This interval should be recognized as the optimal interval for forward conditioning in this preparation $/ 3,278 \%$.

Figure 2 presents a molecular model that summarizes the data described above and illustrates the presumed mechanism of activity-dependent presynaptic facilitation in Aplysia. This illustration is based on previously published models $/ 66,114,128 /$. Figure $2 \mathrm{~A}$ illustrates a US-alone presentation as would occur during sensitization training. Upon tail stimulation (US), 5-HT is released from a facilitatory interneuron and interacts with its postsynaptic receptor on the siphon sensory neuron. This receptor site is associated with a $G_{S}$ protein that stimulates the activity of adenylate cyclase. The calmodulin binding site on the cyclase remains open due to the lack of $\mathrm{Ca}^{2+}$ elevation necessary for calmodulin activation. Following stimulation, adenylate cyclase catalyzes the production of cAMP from ATP. The moderate activation of PKA by cAMP results in the phosphorylation of $\mathrm{K}^{+}$channels leading to a modest degree of presynaptic facilitation. A parallel transduction pathway, arising from the binding of 5-HT to $\mathrm{G}_{0}$ receptor proteins, stimulates the transient translocation of PKC to the membrane where it phosphorylates a class of 


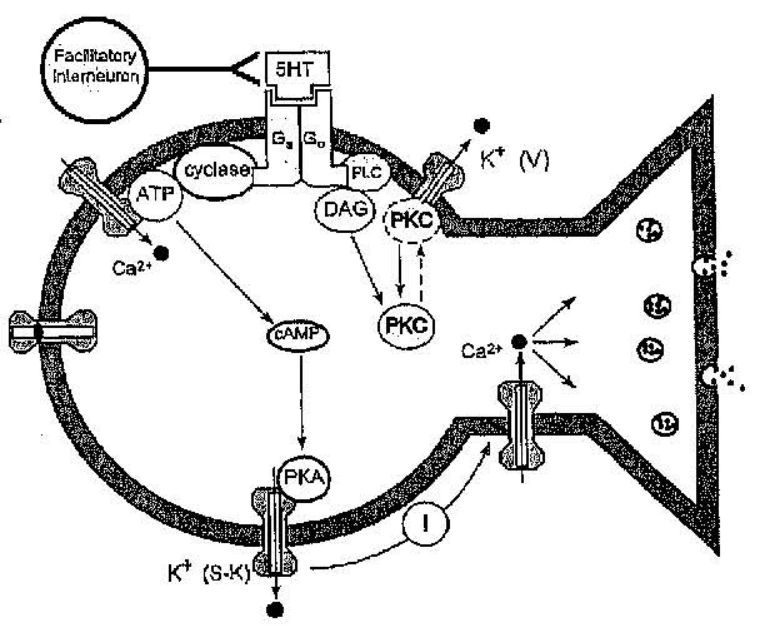

A
Fig. 2: Molecular constituents of activity-dependent facilitation in Aplysia sensory cells.

A. During the presentation of tail shock (as in sensitization training), stimulation of facilitatory interneurons induces a release of 5-HT that binds to two classes of metabotropic receptors $\left(G_{s}\right.$ and $G_{o}$ dependent) on the axon of the siphon sensory neuron (the location of receptors in the figure is only illustrative). The $\mathrm{G}_{\mathrm{s}}$ pathway stimulated by 5 HT induces a small $\mathrm{Ca}^{2+}$ influx through the generation of ATP, which also stimulates the production of cAMP. cAMP weakly activates PKA which phosphorylates the S-K class of $\mathrm{K}^{+}$channel, causing a small and transient reduction of current flow through that channel. The $G_{o}$ pathway stimulted by 5-HT induces a cleavage of PLC which in tum generates DAG, an activator of PKC. (This pathway is also likely to induce $\mathrm{Ca}^{2+}$ release from cytosolic pools, although this has not been demonstrated in these cells.) PKC transiently translocates to the cell membrane and phosphorylates a voltage dependent $\mathrm{K}^{+}$channel, further reducing $\mathrm{K}^{+}$efflux. The weak and transient reduction of these outward $\mathrm{K}^{+}$currents results in a reduced threshold for elicitation, as well as a broadening, of evoked action potentials, ultimately increasing $\mathrm{Ca}^{2+}$ influx in the axon. Through this increase in $\mathrm{Ca}^{2+}$ influx, any subsequent stimulation of the sensory cell will cause an enhancement of transmitter release and the interaction with postsynaptic motor neurons, thus accounting for sensitization.

B. If the siphon is touched just prior to the application of tail shock (as in classical conditioning), stretch receptors in the sensory cell induce a large $\mathrm{Ca}^{2+}$ influx through mechanically-coupled ion channels. This $\mathrm{Ca}^{2+}$ influx (several times greater than is induced by $5-\mathrm{HT}$ binding) greatly potentiates the generation of CAMP from ATP, causing a more effective activation of PKA. Likewise, the higher $\mathrm{Ca}^{2+}$ concentration is presumed to facilitate the activation of PKC by DAG. As a result, PKA and PKC phosphorylate their target proteins more efficiently and the phosphorylation is more persistent. Thus in Aplysia, the facilitation of the synaptic interaction between sensory and motor neurons that underlies classical conditioning is a synergystic consequence of a contiguous rise in intracellular $\mathrm{Ca}^{2+}$ concentration (CS induced) and stimulation of Gprotein coupled receptors by $5-\mathrm{HT}$ (US induced) in the sensory cells. 
voltage-dependent $\mathrm{K}^{+}$channels. If the facilitatory transmitter release is preceded by an elevation in intracellular $\mathrm{Ca}^{2+}$, an amplification of this biochemical response system is observed. Figure 2B illustrates the cellular events underlying paired CSUS presentations. Consequent to the voltagedependent elevation of postsynaptic $\mathrm{Ca}^{2+}$ levels, $\mathrm{Ca}^{2+} / \mathrm{calmodulin}$ binds to adenylate cyclase causing an enhanced production of cAMP and a potentiation in activated levels of PKA, while PKC binding in the neuronal membrane is presumably enhanced and prolonged by the same elevation of $\mathrm{Ca}^{2+}$ (although this latter assumption is untested). The result of this sensory convergence is a $\mathrm{Ca}^{2+}$-dependent enhancement and prolongation of the effects of presynaptic facilitation. As a consequence, the CS-induced withdrawal reflex is amplified relative to both naive and sensitized animals, indicative of an associative "memory".

Interestingly, the relative contribution of PKA and PKC to facilitation appears to depend on the history of the sensory-motor synapse (for a review see /54/). In previously untreated synapses, 5HTinduced facilitation of evoked transmitter release is blocked by inhibitors of PKA, although in depressed synapses, PKC inhibitors are more effective /112/. Moreover, the involvement of these second messengers was also dependent on the time at which the inhibitors were applied after 5-HT application. PKA inhibitors attenuate facilitation immediately or soon after 5-HT application /129/ whereas PKC inhibitors are effective at later times $/ 257 /$. The time dependence of the PKA and PKC effects was corroborated with data obtained using two dimensional gel electrophoresis evaluating degree of phosphorylation. These studies found that the effects of brief 5-HT exposure on protein phosphorylation could be mimicked by cAMP exposure but not by phorbol esters $1259 /$, whereas the effect of long 5-HT exposures was only replicated with phorbol esters $/ 130 /$. Analysis of the biophysical effects induced by these two kinases also showed that their effects could be dissociated. While PKA appears to exert its effects on $I_{K S}$ and $I_{K V}, P K C$ only affects $\mathrm{I}_{\mathrm{KV}} / 257 /$.

The time dependence of facilitation produced by PKA and PKC is of particular importance due to the fact that PKC appears to underlie an intermediate type of memory that links short and long-term processes. In the Aplysia nervous system two phorbol ester sensitive isoenzymes have been identified, Apl I, a Ca ${ }^{2+}$ dependent isoform, and Apl II, a $\mathrm{Ca}^{2+}$ independent isoform /147/. While short term facilitation leads to the activation of Apl I, intermediate facilitation leads to the activation of Apl I and an autonomous kinase, which arises from Apl II 1276/. Activation of PKC during this intermediate period of time is paralleled by an increase in cell excitability (evoked spike rate) that is independent of protein synthesis /175/.

The molecular events that underlie the presynaptic modifications of Aplysia sensory neurons during associative learning were originally referred to as "activity-dependent amplification" of presynaptic facilitation $/ 124 /$, and this description, or close variants of it, is typically used to refer to this mechanism. Although many of the individual components of this mechanism differ in detail from those to be described in the following sections, there is also a clear emergence of many critical similarities. Given these similarities, these seemingly disparate mechanisms might best be viewed as variants of the theme exemplified by activitydependent facilitation.

It should be noted that recent evidence suggests that modifications of the postsynaptic motor neuron (see Figure 1) might contribute to some forms of facilitation at the sensorimotor synapse in Aplysia. This conclusion is warranted by the observations in cell culture that conjoint activity in the sensory neuron and the motor neuron induces at least a short-term form of synaptic facilitation between them, and that this facilitation is attenuated by chelation of $\mathrm{Ca}^{2+}$ in the postsynaptic motor neuron $131,114,195 /$. Moreover, this form of potentiation can be blocked by antagonists of glutamate, an isoform of which appears to mediate the interaction between the sensory cell and the motor neuron 1161\%. Although these earlier experiments were conducted in integrated sensory-motor cultures, a recent experiment makes an important connection between these results and the induction of memory during associative training in Aplysia. Using an in vitro associative conditioning procedure like those previously used to elucidate activity-dependent amplification of presynaptic facilitation /124/, Murphy and Glanzman /196/ have reported that NMDA receptor antagonists disrupt synaptic 
enhancement at the sensory-motor synapse, but had no effect on the enhancement (presumably presynaptic) that followed nonassociative (sensitization) training. These results suggest that the synaptic enhancement which underlies the associative memory may involve post- as well as presynaptic modification. Although the presynaptic mechanism of facilitation described above is apparently sufficient to account for the behavioral modifications indicative of memory, these data suggest the possibility that the story is not yet complete and that memory storage may involve the complex interaction of several mechanisms. These results remind us of the caveat by Glanzman /114/ that classical conditioning, even in such "simple" systems, is clearly not as simple as we may have believed.

The warning by Glanzman /114/ that the cellular basis of classical conditioning in Aplysia may not be "simple" can certainly be applied to either of the remaining models contained in this review. However, since the molecular constituents of learning in Aplysia are more clearly delineated than in Hermissenda or hippocampal LTP, the evidence that learning in Aplysia cannot be subsumed by a single mechanism is a clear reminder that learning mechanisms, like its processes $1222,223,269 /$, are not yet well delineated. For instance, the "simple" network purported to subserve defensive conditioning in Aplysia (see Figure 1) suggests that a well delineated circuit underlies the generation of the gill-withdrawal reflex. However, it has been reported that Aplysia's gill withdrawal reflex is not likely to arise from activity in a small, dedicated circuit. Rather, the gill withdrawal response involves at least 1000 cells distributed in at least three distinct ganglia 1264,273/. Likewise, Colebrook and Lukowiak /68/ trained the semi-intact Aplysia to express a conditioned gill withdrawal teflex using parameters developed in earlier studies $/ 45,124 /$. Jnlike earlier demonstrations, Colebrook and , ukowiak simultaneously recorded the amplitude of ie conditioned gill-withdrawal reflex and the nhanced EPSP in the gill motor neuron (presumably indicative of presynaptic activity-dependent facilitation). Across animals, the amplitudes of the EPSPs and the gill-withdrawal reflex were enhanced; however, no evidence of a correlation between the two responses was detected. This suggested to Colebrook and Lukowiak that multiple mechanisms contribute to the generation of the conditioned response in Aplysia, and that no single mechanism or locus of change was necessary or sufficient to support learning (also see /164/). Given the apparent disparity within a model system, results such as these might suggest a certain futility in attempting to discern common themes arising from the comparison of different model systems. On the other hand, an opposite consideration is raised by this intrinsic diversity. We will take the position that in light of such diversity, it is the commonalities that are expressed across systems that are likely to be most critical to our understanding of the molecular properties of experience-dependent plasticity.

\section{LEARNING IN HERMISSENDA}

Prior descriptions of learning-related neuronal modifications in Hermissenda have been somewhat preliminary. However, recent work has more fully elucidated the underlying mechanisms of learning in this system, and we will provide a complete summary of those data here.

\subsection{Behavioral processes of associative learning in Hermissenda}

Several of Hermissenda's responses to light are subject to modification using a simple associative learning paradigm in which a light (CS) is paired with rotation or water turbulence (US). These modifications of phototactic behavior have been observed following paired, but not unpaired or random, presentations of light and rotation, and can persist for days following 150 pairings spread over 3 days $/ 79 /$, or for several weeks following more extensive training $/ 122,180 /$. As with Aplysia, associative learning in Hermissenda exhibits many of the characteristics of traditional vertebrate conditioning preparations, including sensitivity to the contingency and temporal order of the CS and US $/ 96,117 /$, interstimulus interval $/ 188 /$, extinction $/ 226 /$, facilitated reacquisition following degradation of memory $/ 79,180 /$, and a deficit in learning as a consequence of massed training trials $/ 197,231 /$.

Numerous measures have been used to index phototaxic behavior in Hermissenda, including light-initiated locomotion $/ 78,98 /$, orientation 
towards a light source $/ 79 /$, and locomotion within a light gradient 196,98/. Light-induced phototaxic behavior is accompanied by an extension of the animal's muscular "foot", its organ of locomotion. In contrast to its responses to light, exposure to rotation elicits unconditioned responses that are opposite in nature to those elicited by light, i.e., reduced rate of locomotion and contraction of the foot $179,154,187 /$. Lederhendler et al. /154/ demonstrated that a light CS comes to elicit a foot contraction (CR) following paired presentations of light and high-speed rotation, suggesting that the conditioned response reflected the transference of some of the properties of the US (rotation) to the CS (light). A similar effect was reported by Matze] et al. $/ 187 /$, who demonstrated a strong correlation between conditioned reductions in phototaxis and conditioned foot contraction, although the former was more subject to nonassociative modification suggesting some degree of dimorphism between the responses. Lederhendler et al. and Matzel et al. speculated that conditioned foot contraction served a "preparatory" role $/ 154,187,215 /$, reducing the likelihood that rotation would dislodge the animal from its substrate. This speculation received support with the demonstration that animals for which rotation is predicted by light cling more effectively to their substrate during a period of rotation $/ 231$.

The behavioral analysis of association formation in Hermissenda has aided the development of a model system that, like Aplysia, shares a host of similarities with analogous vertebrate learning and yet provides the simplicity and specificity to investigate the network, cellular, and molecular components of that learning. Prior to any description of the molecular constituents of this learning, we will describe the interaction of visual and vestibular systems in Hermissenda as well as the mechanisms of sensory transduction in these systems.

\subsection{Network interactions underlying Hermissenda associative learning}

Sensory information about the light CS and rotation US is transduced in the Hermissenda nervous system through a symmetrical pair of eyes and statocysts. Previous work has elucidated numerous intersensory interactions between these sensory systems as well as within the sensory-motor networks $18,82,84 /$. A simplified version of the neural network underlying these interactions and classically conditioned responses in Hermissenda is depicted in Figure 3.

Light (CS) Pathway. Visual information about the $\mathrm{CS}$ is encoded through the eyes of the Hermissenda which each contain five photoreceptors that are situated within a lattice of nonneuronal pigment cells 189\%. These photoreceptors have been distinguished electrophysiologically into two type A and three type B photoreceptors /13/. Type B receptors exhibit synaptically mediated, reciprocal inhibition with each other and more weakly inhibit type A photoreceptors /82/. Light-evoked responses in type $A$ and $B$ photoreceptors consist of complex potential changes carried by selective alterations in ion permeability $/ 83,97 /$. An early, peak depolarization of the $\mathrm{B}$ photoreceptor in response to light is carried by an inward, light-activated $\mathrm{Na}^{+}$current ( $\left.\mathbf{I}_{\mathrm{Na} \text {-light }}\right)$ that is opposed by a fast, rapidly inactivating outward potassium current $\left(\mathrm{I}_{\mathrm{A}}\right)$. Following the peak response, the light-induced depolarization begins to reverse and then plateaus at an intermediate level of depolarization. A sustained depolarization during light is maintained by a lightactivated, nonspecific cation currents $\left(\mathrm{I}_{\text {cation }}\right)$ as well as a voltage-dependent $\mathrm{Ca}^{2+}$ current $\left(\mathrm{I}_{\mathrm{ca}}\right)$. These depolarizing currents are opposed in part by voltage and $\mathrm{Ca}^{2+}$-dependent potassium currents $\left(\mathrm{I}_{\mathrm{KV}}\right.$ and $\mathrm{I}_{\mathrm{KCa}}$ ).

Axons from all five photoreceptors exit the eye and send projections to motor neurons via an ipsilateral optic ganglion and efferent interneurons. Although these interneurons are known to project onto motor neurons which innervate the foot, the interactions between interneurons as well as their efferent pathways have been only partially characterized $/ 5,116,225 /$.

Rotation (US) Pathway. Early morphological analysis revealed that the statocyst was a spherical structure formed by 13 ciliated hair cells which when acted upon by centrifugal forces, are mechanically displaced by statoconia suspended within the cyst $/ 150 /$. In response to this stimulation, hair cells exhibit a depolarizing generator potential. Axons from the hair cells travel to the neuropil of the ipsilateral cerebropleural ganglion where they give rise to terminal branches 


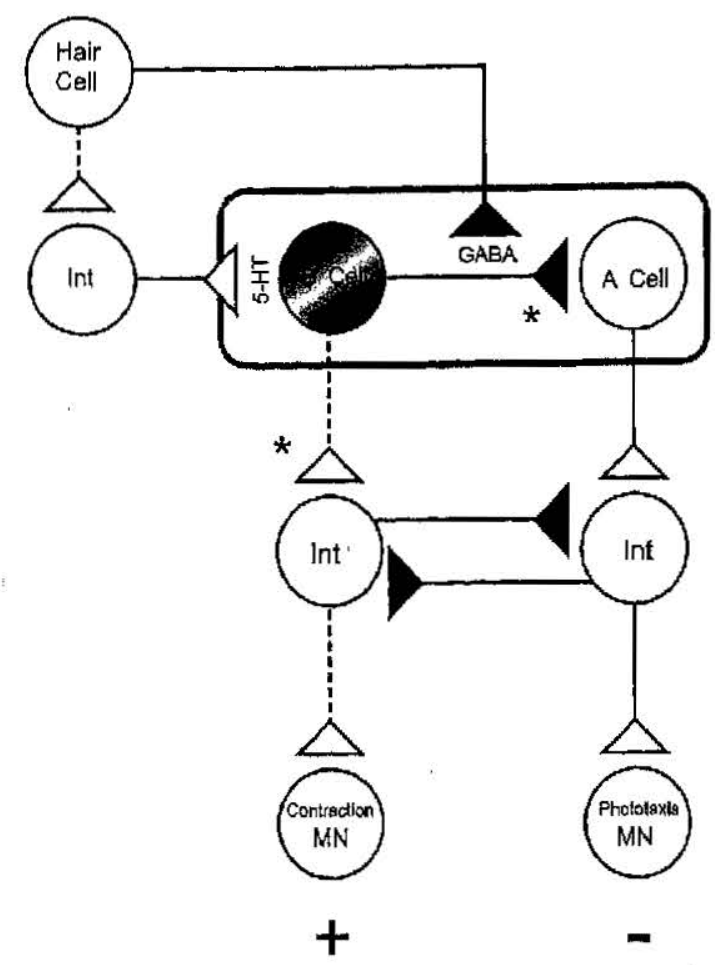

Fig. 3: A simplified depiction of the neural network that underlies associative learning in Hermissenda. During associative conditioning, light (CS) depolarizes the type $A$ and type $B$ photoreceptors and the mechanical perturbation of cilia induced by rotation (US) depolarizes and induces action potentials in the hair cells. Hair cells monosynaptically project onto the photoreceptor axons where they release GABA. It is also presumed, though not confirmed (dashed line) that the hair cells stimulate interneurons (INT) which project onto the $B$ cell soma and release 5-HT. The binding of GABA and/or 5-HT to the B cell during a period of light-induced depolarization induces a persistant increase in the excitability of the $B$ cell which in turn facilitates (*) its inhibitory synaptic interaction with the A photoreceptors as well as a presumed, though not well characterized (dashed line) direct projection onto interneurons. As a result, subsequent light presentations bias the output of the eye toward the B photoreceptor, shunting A cellmediated phototactic responses to light and inducing an otherwise sublimated foot contraction. It should be explicitly noted that the lightresponsive interneuronal network is quite complex and not well characterized. Given that unidirectional, bidirectional, excitatory, inhibitory, or polysynaptic interactions exist between each of at least 24 such interneurons, the depiction of this network is only illustrative, although it is at least consistent with known pathways and can account for the behavioral modifications that reflect associative learning. and project monosynaptically onto ipsilateral photoreceptors $/ 115 /$, as well as central visual interneurons $15 /$. Depolarization of the caudal hair cells results in a hyperpolarization in the $B$ photoreceptor. This hyperpolarization can be as large as $-12 \mathrm{mV}$ at resting potentials and is accompanied by a cessation of spontaneous spikes in the photoreceptor $/ 11,228 \%$. This inhibitory response of the photoreceptors to statocyst stimulation is mediated by $\mathrm{GABA}$ Aergic receptors localized in the terminal region of the B photoreceptor's axon $111,179,228 /$. Although there was some initial confusion concerning the basis of the postsynaptic response to GABA, it is now clear that this response is mediated in large part by an increase in $\mathrm{K}^{+}$conductivity in that the response is dependent on extracellular $\mathrm{K}^{+}$but not $\mathrm{Cl}^{-}$, reverses between -80 and $-90 \mathrm{mV}$ (the reversal potential for $\mathrm{K}^{+}$), and is mimicked by the $G_{A B A}$ receptor agonist baclofen /184/. GABA receptor antagonists have proven to be only weakly effective in blocking the postsynaptic response, although $\mathrm{GABA}_{B}$ receptor antagonists have had the most consistent effect $1228 /$, and the $\mathrm{K}^{+}$channel blocker TEA completely eliminates the response $/ 24,184 /$. Consistent with its apparent similarity to $\mathrm{GABA}_{B}$ receptors, the inhibitory response of the $\mathrm{B}$ cell to micro application of GABA or to hair cell stimulation is attenuated by intracellular injections of nonhydrolyzable forms of GDP /228/, strongly suggesting that the receptor affects postsynaptic channels via a G-protein coupling mechanism.

At the level of the central visual interneurons, hair cell stimulation can result in either excitation or inhibition depending on the target cell $/ 5 /$. While the functional significance of these synaptic interactions has not been determined, the stimulation of interneurons by the hair cells is a potential source of polysynaptic serotonergic projections onto the soma membrane of the B cell. Serotonergic fibers have been reported to pass in close proximity to the eye $125,151 /$, and pressure micro application of $5 . \mathrm{HT}$ indicates that receptors are present on the soma of the B photoreceptors, but not on terminal fibers 1229/. Rogers and Matzel /229/ reported that 5-HT micro application to the soma induces two distinct depolarizing responses. A strong depolarization (often $+10 \mathrm{mV}$ or more when measured at resting potentials) peaks rapidly $(1-2 \mathrm{sec})$ and dissipates 
within several seconds. A distinct smaller depolarization appears as the initial depolarization wanes, and dissipates at a slower rate. The ionic bases of these responses are complex, apparently being carried by both decreases in basal $\mathrm{K}^{+}$currents, an increase in a $\mathrm{Ca}^{2+}$ current, and an increase in one or more unidentified current $/ 4,104,229,275 /$. A clear understanding of the integrative contribution of these currents to the depolarizing response has not emerged, in part owing to their separate interactions with membrane voltage and their complex temporal dynamics $/ 229 /$. This characterization has proven particularly difficult in that the (presumed) serotonergic neurons which project onto the eye have not yet been identified, precluding any examination of serotonergic responses in the photoreceptor under physiological conditions. It is important to note, however, that both fast and slow depolarizing voltage responses of the $\mathrm{B}$ cell to 5 -HT micro application are eliminated by intracellular injection of nonhydrolyzable GDP, indicating their G-protein dependence. Since the voltage response of the B cells to 5-HT micro application has only recently been described $/ 229 /$, systematic studies of the effectiveness of 5-HT receptor antagonists have not been conducted. Based on its G-protein dependence and electrophysiological properties, Rogers and Matzel /229/ suggested that this receptor was most analogous to the $5-\mathrm{HT}_{2}$ receptor subtype.

\section{Transduction of visual (CS) and vestibular (US)} stimulation in the B photoreceptors. Light induces a depolarization in the $\mathrm{B}$ photoreceptors through a somewhat unusual molecular cascade. Unlike common photo transduction cascades which require the coupling of rhodopsin to a G-protein $/ 105,214 /$, stimulation of rhodopsin in the B photoreceptor appears to directly stimulate phospholipase C (PLC) 1234/ which in turn hydrolyses $\mathrm{PIP}_{2}$. This is demonstrated by the observations that injections of GTP or nonhydrolysable analogs of GDP /234/, as well as incubation with the G-protein activator aluminum fluoride $/ 186 /$, have no effect on the depolarizing light response, while phosphoinositide turnover inhibitors eliminate the light response $1234,261 /$. As illustrated in Figure 4, light stimulates the degradation of $\mathrm{PIP}_{2}$ into $\mathrm{DAG}$ and $\mathrm{IP}_{3} / 205 /$. Although these second messengers can play important regulatory roles, Sakakibara et al. /234/ reported that $\mathrm{PIP}_{2}$ directly interacts with $\mathrm{Na}^{+}$ selective channels, suggesting no role for $\mathrm{IP}_{3}$ or DAG on the early light-induced depolarization.

The depolarizing response to light induces a large increase in intracellular $\mathrm{Ca}^{2+}$ concentration 172,260/. This increase in free $\mathrm{Ca}^{2+}$ derives in small part from a voltage-dependent activation of inward $\mathrm{Ca}^{2+}$ currents, but is more heavily attributable to the $\mathrm{IP}_{3}$-dependent release of $\mathrm{Ca}^{2+}$ from intracellular stores $1199,260 /$. This liberation of $\mathrm{Ca}^{2+}$ from cytosolic sequestration contributes to the maintenance of the generator potential and acts to slow the repolarization to resting membrane potentials after light offset. Moreover, the liberation of DAG concomitant with the $\mathbb{P}_{3}$-induced rise in intracellular $\mathrm{Ca}^{2+}$ is likely to transiently activate protein kinase $\mathrm{C}$ (PKC) 1205,209\%. Since PKC phosphorylates voltage- and $\mathrm{Ca}^{2+}$-dependent $\mathrm{K}^{+}$channels in these cells $/ 15,101 /$, the combined generation of these second messengers is likely to contribute to a transient reduction of $\mathrm{K}^{+}$conductance that occurs during the light response $/ 12,14,18 /$, thus minimizing the opposition to the light-induced depolarization that these $\mathrm{K}^{+}$currents would otherwise exert. The transduction cascade underlying the light response in the $\mathrm{B}$ cell is summarized in Figure 4A. It should be explicitly stated that most of our understanding of the light transduction cascade has come from electrophysiological studies of the effects of various pharmacological agents on the light-induced depolarization. Although such techniques are valuable in that they permit the assessment of responses in the intact nervous system, the precise nature of these cascades is in part speculative owing to the poor selectivity of pharmacological agents. Thus a complete elucidation of these cascades awaits the necessary biochemical analyses.

The transduction cascade that mediates GABAergic responses in the $B$ cell is illustrated in Figure $4 \mathrm{~B}$. In contrast to the independence of the light response on G-proteins, both GABAergic and serotonergic responses in the $\mathrm{B}$ cell require the stimulation of a receptor-coupled G-protein /148, 228/. Given that serotonergic cells that innervate the eye have not been identified, little is known about the transduction of indigenous serotonergic responses. It appears though that the 5-HT and $\mathrm{GABA}_{B}$ receptors on the $B$ cells may stimulate a similar 


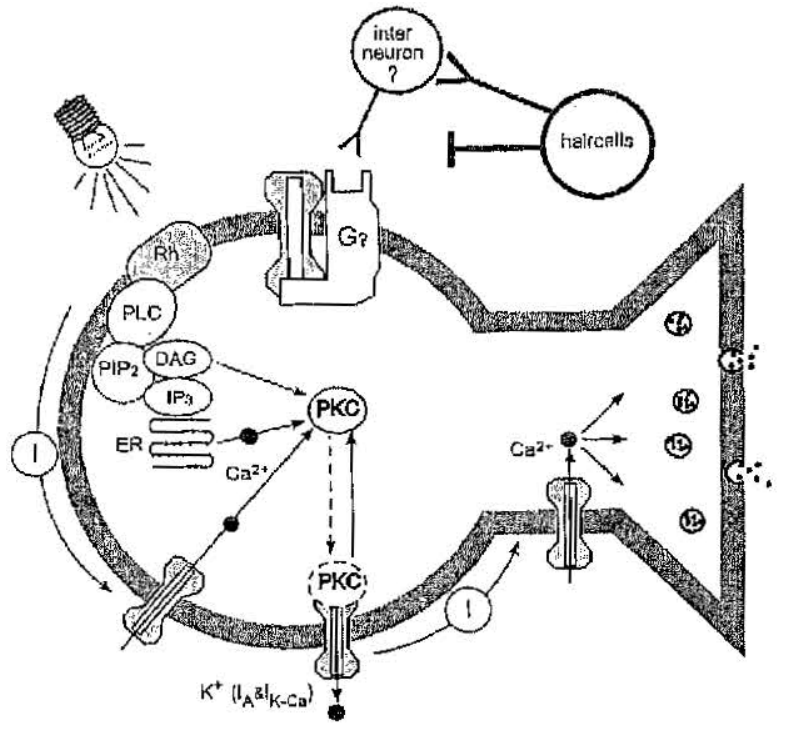

A

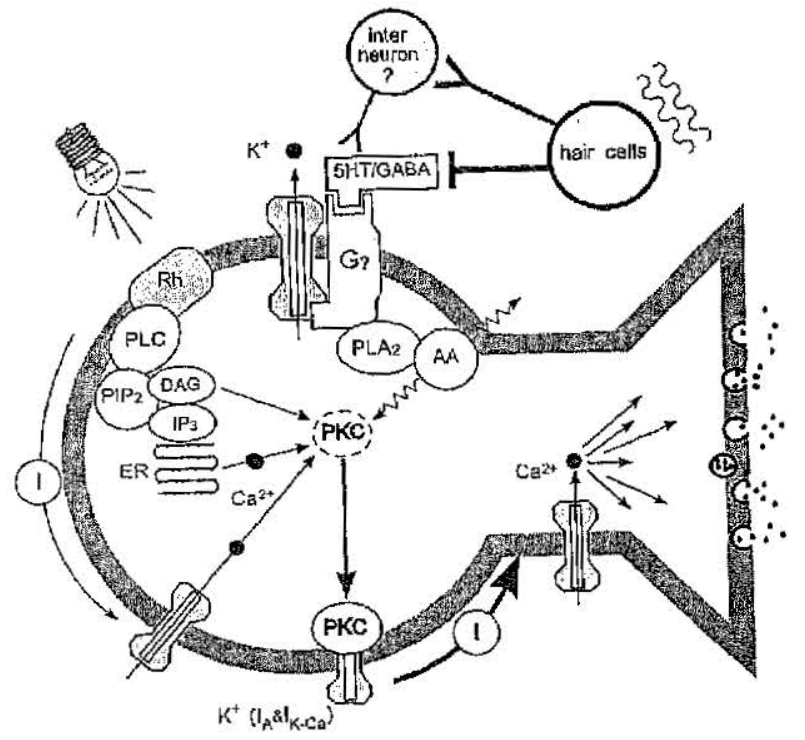

B
Fig. 4: Molecular constituents of activity-dependent facilitation in Hermissenda B cells. A. Presentation of light stimulates a transduction cascade which ultimately cleaves $\mathrm{PIP}_{2}$ into $\mathrm{IP}_{3}$ and DAG. Lightinduced depolarization of the $\mathrm{B}$ cell is initiated by a direct interaction of $\mathrm{PIP}_{2}$ with nonvoltage-sensitive $\mathrm{Na}^{2+}$ channels (not shown), and this depolarization stimulates voltage-gated $\mathrm{Ca}^{2+}$ channels, resulting in an influx of $\mathrm{Ca}^{2+}$. In addition, a larger (several fold) intracellular $\mathrm{Ca}^{2+}$ signal arises from an $\mathrm{IP}_{3}$ mediated release from intracelitular stores (assurned, though not confirmed, to be rough endoplasmic reticulum; ER). The combined action of high $\mathrm{Ca}^{2+}$ concentration and free DAG activates PKC which forms a weak and transient association with the neural membrane where it phosphorylates and reduces conductance through two classes of $\mathrm{K}^{+}$ channels. This reduction in $\mathrm{K}^{+}$conductance returns to normal levels shortly after light offset, and is likely to occur so as to reduce opposition of the light-induced depolarization. B. Hair cell activity stimulates the release of GABA and 5-HT onto Gprotein coupled receptors. (These receptors are not colocalized as depicted here; see Figure 3 for relative locations. Moreover, 5-HT and GABA appear to modulate different classes of $\mathrm{K}^{+}$channels, shown here as one channel for simplicity.) Both the synaptic responses to GABA and 5-HT binding are dependent on unknown classes of G-proteins, and the response to GABA is known to stimulate PLA $A_{2}$ and a resultant generation of free $A A$. In these cells, $\mathrm{Ca}^{2+}, \mathrm{DAG}$, and AA act synergystically to produce a nore effective activation of $\mathrm{PKC}$ (or of unique $\mathrm{PKC}$ isoforms) which is likely (though not yet demonstrated in this cell type) to bind to the neural membrane until undergoing degradation. As a result of this potentiated activation and translocation of PKC to the membrane, $\mathrm{K}^{+}$conductance is further reduced relative to that caused by light alone, and the reduction persists long after light offset. Consequently, the B cell is more responsive to subsequent light exposure, and action potentials are prolonged, resulting in an increase in the release of transmitter and the strength of the synaptic interaction with effector cells. Thus as in Aplysia, the facilitation of synaptic responses during associative learning in Hermissenda is a synergystic consequence of a contiguous rise in intracellular $\mathrm{Ca}^{2+}$ (CS induced) and stimulation of G-protein-coupled receptors (US induced). Note that normal transmission between the hair cell and the $B$ cell is not affected by associative training as the class of $\mathrm{K}^{+}$channel that mediates that interaction is not phosphorylated by PKC. 
class of G-proteins $/ 229 /$, as they sometimes do in other cell types $121 \%$. In contrast to the 5-HT response, hair cell-induced hyperpolarization of the eye has been relatively well characterized. Interestingly, in mammalian cells, $\mathrm{GABA}_{B}$ receptors stimulate a slow hyperpolarization via a G-proteininduced stimulation of phospholipase $\mathrm{A}_{2}\left(\mathrm{PLA}_{2}\right)$ and a resultant stimulation of $\mathrm{K}^{+}$channels $/ 87,111 /$. We have suggested $/ 228 /$ that the GABA-induced hyperpolarization was sufficiently fast (peaking in less than $50 \mathrm{msec}$ ) that the $\mathrm{G}$-protein might be directly coupled to the postsynaptic $\mathrm{K}^{+}$channels (see $/ 49,63 /$ for a review of similar metabotropic receptors). More recently, it has been reported that the inhibition of $\mathrm{PLA}_{2}$ with quinacrine has no effect on the hair cell-induced hyperpolarization of the $\mathrm{B}$ cell $1261 /$, further suggesting that the G-protein might directly modulate $\mathrm{K}^{+}$channels without an intermediary phosphorylation event. Although not required for the GABA-induced hyperpolarization in these cells, $\mathrm{PLA}_{2}$ may contribute to the small reduction of voltage-dependent $\mathrm{Ca}^{2+}$ currents induced by both GABA /275/ and baclofen /184/, as well as the 5-HT-induced depolarization that we have observed. These latter suppositions have not been tested, although it does appear that GABA binding generates $\mathrm{PLA}_{2}$ (discussion below; see (231/). It should also be noted that pertussis toxin, which in other cell types inactivates certain Gproteins (e.g., $G_{\mathrm{D}}$ and $\mathrm{G}_{\mathrm{i}}$ ) including that which couples the $\mathrm{GABA}_{B}$ receptor to its effectors $121,88 /$, has no effect on GABA responses or hair cell-induced hyperpolarization in the B cell, whether microinjected for 14 hours (unpublished observations) or incubated for up to 26 hours $/ 228 /$. Similarly, cholera toxin (which commonly inhibits $\mathrm{G}_{\mathrm{s}}$ and $\mathrm{G}_{\text {transducin }}$ ) was without effect on these responses (Rogers and Matzel, unpublished observations). Given the rather unique properties of this receptor, it is perhaps not surprising that $\mathrm{GABA}_{B}$ receptor antagonists are only weakly effective in attenuating the GABA-induced hyperpolarization.

\subsection{Stimulus convergence and learning-induced neuronal facilitation in the $B$ photoreceptor}

Following associative learning, Hermissenda $\mathrm{B}$ photoreceptors exhibit a general increase in excit- ability that is characterized by an increase in input resistance $/ 181,272 /$, an increase in the amplitude of the light-induced generator potential as well as the amplitude and duration of the long-lasting depolarization after the offset of light $/ 75,80,100,272 /$, an increase in evoked spike frequency $/ 230 /$, and an increase in the synaptic efficacy between the B cell and its efferent targets $/ 110,239 \%$. It has recently been found that associative learning is also accompanied by an increase in the height and width of evoked action potentials in the B cell /157/. All of these indices of facilitation are believed to arise from a reduction of voltage- and $\mathrm{Ca}^{2+}$-activated $\mathrm{K}^{+}$ currents $/ 17,69,97 /$ in the soma membrane, although Clark and Schuman $166,239 /$ have suggested that some component of synaptic facilitation may be synapse specific. Nevertheless, the modifications of $\mathrm{K}^{+}$currents as well as synaptic facilitation appear to be induced by the sustained activation of PKC, in that bath application or microinjection of PKC and its activators into the $\mathrm{B}$ cell causes a similar reduction of currents $/ 15,101,239 /$, and the inhibition or down-regulation of PKC blocks the traininginduced increases in excitability $176,103,183$. Moreover, a training-induced translocation of PKC from its inactive state in the cytosol to its active state in the membrane has been directly observed using autoradiographic techniques /191/, and we have recently reported that $\mathrm{Ca}^{2+}$-dependent PKC isoforms are incrementally translocated to the neuronal membrane with successive in vitro training trials. In this latter case, the translocation of PKC was extremely well correlated with an incremental increase in several indices of neuronal excitability /198/.

It had been previously suggested that the neuronal facilitation that accompanies learning in Hermissenda arose from network interactions that produced a progressive depolarization of the $\mathrm{B}$ cell that accumulates with successive pairings of light and rotation 19/. This "cumulative" depolarization was thought to result in a sustained increase in free $\mathrm{Ca}^{2+}$ levels, which in turn was proposed to activate PKC and/or other $\mathrm{Ca}^{2+}$ sensitive kinases $19,10,100 /$. While the requirement for increases in intracellular $\mathrm{Ca}^{2+}$ concentration has been confirmed 195,185 , $260 /$, we have demonstrated that the cumulative depolarization in the $\mathrm{B}$ cell that accompanies learning does not contribute to the induction of 
facilitation in that ceil. In fact, the cumulative depolarization tends to interfere with the induction of the biophysical memory trace due to the sustained inactivation of voltage-dependent $\mathrm{Ca}^{2+}$ currents $/ 185,231 /$ and/or the preferential stimulation of protein phosphatases /197/. Since presynaptic stimulation of the hair cells coincident with a light-induced rise in intracellular $\mathrm{Ca}^{2+}$ in the $\mathrm{B}$ cell is necessary for the induction of a sustained increase in excitability, we have more recently suggested that the interaction of postsynaptic activity concomitant with stimulation of a metabotropic receptor underlies the induction of learning-induced facilitation in the B cells.

Available evidence strongly suggests that learning-induced modifications of the B photoreceptor result from the concomitant binding of GABA and/or 5-HT (US signal) to the B cell during periods of light-induced $\mathrm{Ca}^{2+}$ elevation (the $\mathrm{CS}$ signal). The convergence of these two signals from the CS and US pathways must induce a long-lasting modification of $\mathrm{K}^{+}$conductance across the $\mathrm{B}$ cell nembrane that neither signal alone can account for, cause neither repeated presentations of the CS d US alone, nor their unpaired presentation, sults in any long-lasting modification of the B cell. transduction cascade which satisfies this requirenent and which is consistent with the data reviewed here is illustrated in Figure 4B. This model requires no assumptions about complicated network interactions (e.g., cumulative depolarization) and is consistent with signaling pathways described in this and many other cell types. As described above, light alone is sufficient to activate PKC in the $B$ cell via the simultaneous liberation of $\mathrm{DAG}$ and $\mathrm{IP}_{3}$, a common route of activation which results in a relatively loose and short-lived association of the enzyme with the neuronal membrane /205/. This role of $\mathrm{PKC}$ is consistent with the observation that voltage- and $\mathrm{Ca}^{2+}$-activated $\mathrm{K}^{+}$channels are transiently suppressed during the light response, but quickly return to baseline after light offset. Clearly, such a mechanism is not sufficient for the sustained reduction of $\mathrm{K}^{+}$currents associated with memory storage in these cells.

Since the activation of PKC has been strongly implicated as mediating the long-lasting reduction of $\mathrm{K}^{+}$currents that underlie memory storage in Hermissenda, these results have been viewed as somewhat perplexing. A 1991 report shed some light on this anomaly /156/. Lester et al. reported that analogs of DAG were only weakly effective in inducing a reduction of $\mathrm{K}^{+}$currents across the $\mathrm{B}$ cell membrane. However, the combined application of $D A G$ analogs and the fatty acid arachidonic acid (AA) caused a far greater reduction of the same currents. Interestingly, this signaling mechanism had recently been delineated by Nishizuka, who has demonstrated that the combined stimulation of PKC by DAG and AA induces a more stable bond between the kinase and the neuronal membrane which long outlasts the initial signals, possibly persisting until the kinase undergoes normal degradation $/ 205 /$.

At the same time that Nishizuka had observed the synergistic effects of DAG and AA on PKC activation, some of the general characteristics of GABA-activated G-protein coupling mechanisms were becoming apparent. Importantly, Axelrod and his colleagues $126,50 /$ had reported that the Gprotein that coupled the $G A B A_{B}$ receptor to its postsynaptic effectors stimulated the activation of $\mathrm{PLA}_{2}$, which through hydrolysis releases AA from its chemical linkage in the phospholipid bilayer. In the Hermissenda $\mathrm{B}$ cell and other cell types, AA is a weak or ineffective activator of $\mathrm{PKC}$, though, as stated above, it can act synergistically with DAG to activate the kinase. Consequently, it appears that the strong and persistent activation of $\mathrm{PKC}$ by the convergence of $\mathrm{Ca}^{2+}, D A G$, and $A A$ during contiguous presentations of light and rotation might be sufficient to account for activity-dependent neuronal facilitation.

In support of this proposal, it has been reported that inhibition of the PLC signaling pathway eliminated light-induced depolarization in the B cell $1234,261 \%$. However, consistent with our assumption that the receptors which mediate hair cellinduced hyperpolarization stimulate a G-protein that is directly coupled to a $\mathrm{K}^{+}$channel, inhibition of PLC or PLA $\mathrm{A}_{2}$ had no effect on the hyperpolarizing response. Nevertheless, inhibition of both $\mathrm{PLA}_{2}$ and AA breakdown blocked the increase in excitability that normally accompanies in vitro pairings of light and mechanical stimulation of the hair cells. This leads to the conclusion that although the G-protein that affects the postsynaptic hyperpolarization is directly coupled to a $\mathrm{K}^{+}$ionophore, it activates 
$\mathrm{PLA}_{2}$ as it does in other cell types, probably as a first step in other signaling pathways as described above. While these electrophysiological studies allow us to infer characteristics of this cascade, recently begun studies in our laboratory have confirmed that PLA $\mathrm{A}_{2}$ and GABA do indeed induce a rise in levels of free $\mathrm{AA}$ as indexed by fluorescent labeling (Ghandi, Talk, Muzzio, and Matzel, unpublished observations), providing further support for this hypothesis.

Although the above results are all consistent with the assertion that the convergence of $\mathrm{AA}$, $\mathrm{DAG}$, and $\mathrm{Ca}^{2+}$ prolongs the insertion of $\mathrm{PKC}$ into the lipid membrane (and thus its phosphorylation of $\mathrm{K}^{+}$channels), these results do not provide unique support for this hypothesis. It has become clear in recent years that "PKC" is not a single enzyme, but instead represents a family of distinct isoforms 1200/. The various isoforms in the PKC family exhibit distinct sensitivities to various combinations of each of these activators, and the route of activation as well as the isoform stimulated is a critical determinant of the enzyme's activity. Thus there are numerous routes by which the convergence of AA (as provided by rotation) and $\mathrm{Ca}^{2+} / \mathrm{DAG}$ (as provided by light) might influence the sustained activity of PKC, depending on the isoenzyme expressed in the target cell, and further work will be required before this signaling pathway is fully elucidated in Hermissenda B photoreceptors. A detailed discussion of the family of PKC isoforms and their routes of activation is provided below in Section 4.4.

It should be noted that associative learning in Hermissenda has been found to cause a two-fold increase in the expression of a $20 \mathrm{kDa}$ G-protein with characteristics similar to V-ras oncoproteins 1201-203/. Isolation of this protein and microinjection into B photoreceptors of untreated animals results in a reduction of the same $\mathrm{K}^{+}$currents reduced by associative training $/ 202 /$. While the exact function of this protein is uncertain, it is interesting to note that oncogene activity is often associated with increased levels of unbound DAG and AA in other cell types $193,94 /$, and thus the expression of this protein induced by associative conditioning may serve to maintain the facilitation of the $\mathrm{B}$ cell for prolonged periods.
Although we have alluded to the role of both GABA and 5-HT in the induction of facilitation in the B photoreceptor, we should explicitly state that we are uncertain as to whether one or both of these transmitters is critical to this process. At present, little is known about the 5-HT signaling cascade (although it is G-protein dependent), and we have added it to our model for illustrative purposes. It should be noted that several reports indicate that 5 HT receptor antagonists (but also agonists) may attenuate the induction of facilitation in the B cell $/ 118 /$, and 5-HT paired with light can induce an increase in several indices of excitability $175,77 /$, but so too can 5-HT application in the absence of light /118/. Based on these data, at least two molecular descriptions of neuronal facilitation in Hermissenda have been proposed that rely exclusively on $5-\mathrm{HT}^{\prime} \mathrm{s}$ role in that process $/ 66,74 /$. Although GABA paired with depolarization can induce short-term increases in B cell excitability /179/, effective antagonism of this GABA receptor has not yet been accomplished, so an assessment of its role in facilitation under physiological conditions is not yet certain. Since both $5-\mathrm{HT}$ and GABA may stimulate a similar class of receptor-coupled G-proteins, it is possible that these transmitters have an additive effect, given that it has been demonstrated that direct stimulation of G-proteins in combination with an increase in intracellular $\mathrm{Ca}^{2+}$ reduces $\mathrm{K}^{+}$conductance in a manner analogous to classical conditioning $/ 186 /$. Although our description of the events underlying learning in Hermissenda are limited by these caveats, they are not critical to our primary objective, which is to illustrate the functional similarity of learning-induced modulation of Hermissenda B photoreceptors to other activitydependent forms of facilitation, a comparison to be made explicit in the conclusion of this paper.

\section{HIPPOCAMPAL LONG-TERM POTENTIATION}

Following a collaboration with Per Anderson, long-term potentiation (LTP) was first formally described by Bliss and Lomo in 1973 /37,38/. LTP is typically expressed as an increase in synaptic efficacy lasting from hours to days following brief tetanic (high-frequency) stimulation of an afferent pathway. Thus, following LTP induction, a constant 
amount of presynaptic stimulation induces a "potentiated" post-synaptic response, e.g., an increase in amplitude of evoked EPSPs. Although LTP is commonly referred to as a likely mechanism of memory storage, direct evidence in support of this claim is not available and available evidence even contradicts this assertion (e.g., $130,121,206$, 236/), leading some to conclude that LTP is poorly suited for this role $/ 190,245 /$. This failure to find conclusive evidence in support of a role for LTP in memory stems in part from the inability to identify single neurons in the marmalian brain, in combination with the extreme complexity of mammalian memory, difficulties not encountered by researchers studying invertebrates. Since the data which link LTP to memory formation are correlational and are subject to multiple interpretations $/ 30,236 /$, we will not attempt to review the evidence here (for recent reviews, see $/ 177,245 /$ ). Nevertheless, LTP in the hippocampal formation provides a convenient preparation to study neuronal or synaptic facilitation in the mammalian brain, and thus provides some point if comparison to the invertebrate models described bove.

Long-term potentiation, in various forms, can be induced at the three major synaptic connections of the hippocampus, a brain region considered critical to the acquisition or processing of some forms of memory 1242/. LTP has been observed in dentate gyrus granule cells following strong stimulation of the perforant path as originally described by Bliss and Lomo $138 \%$, in CA3 pyramidal cells following stimulation of the mossy fibers $17,274 /$, and in CAl pyramidal cells by stimulation of the Schaffer collateral branches of the CA3 neurons $/ 20,241 /$. In addition to its presence in the hippocampus, LTP in various forms has been observed in a wide range of other subcortical as well as cortical brain areas (see 1245 / for review) and can thus potentially play a widespread role in brain plasticity.

Consistent with a point made in the introduction of the present paper, the cellular and molecular events that underlie LTP induction at different synapses within the hippocampal formation and throughout the brain are tremendously diverse, and no single mechanism is representative of the general phenomenon. Thus the term "LTP" has been suggested to have little descriptive value $/ 245 /$. This however illustrates our premise that the specific molecular constituents of any single mechanism are not likely to represent the mechanism underlying the storage of associative (or other) memories. Rather, it may be beneficial to identify a class of features which is conserved across each of these various mechanisms.

\subsection{Postsynaptic $\mathrm{Ca}^{2+}$ and LTP induction}

We focus here on two mechanistically similar and historically prototypical forms of hippocampal LTP which are observed in the dentate gyrus granule cells and CAl pyramidal cells. For simplicity, we often refer to these forms of LTP as "hippocampal LTP", although it is clear that LTP in CA3 pyramidal cells is in some ways dissimilar $1133,134 /$. The forms of LTP that we describe (as well as most characterized forms) share a common requirement for a transient elevation of postsynaptic $\mathrm{Ca}^{2+}$ (but see $1235 /$ ).

Much of the evidence implicating biochemical processes in LTP induction has been inferred from pharmacological manipulations of the phenomenon itself as opposed to having been directly observed biochemically (as was also the case for Hermissenda), leading to many conflicting accounts of the molecular constituents of LTP. Although the exact role of $\mathrm{Ca}^{2+}$ in LTP induction continues to be a matter of some debate, elevation of postsynaptic $\mathrm{Ca}^{2+}$ is clearly necessary and may in some instances be sufficient for its induction. For example, induction of LTP between Schaffer collaterals and CAI pyramidal cells is prevented by a pretetanus injection of $\mathrm{Ca}^{2+}$ chelators into the postsynaptic cell $/ 165,171 /$, and induction occurs when the postsynaptic cell is artificially loaded with the ion /171/. A great deal of evidence (e.g., $/ 70,123 /$ ) indicates that one source of the intracellular $\mathrm{Ca}^{2+}$ signal during the induction of hippocampal LTP arises from influx through an ion channel coupled to the NMDA subtype of glutamate receptor. This receptor is unique in that stimulation of the channel ionophore requires glutamate binding as well as a moderate level of depolarization. At normal resting potentials $(\approx-70 \mathrm{mV})$, the channel is blocked by magnesium ions, and glutamate binding is insufficient to open it. However, at depolarized membrane potentials $(>-40 \mathrm{mV}$ ), magnesium is expelled from the pore, allowing glutamate to open the channel, 
which is primarily permeable to $\mathrm{Ca}^{2+}$ ions. Thus, the NMDA receptor complex is said to be dually regulated by two factors: ligand and voltage. These cofactors can be recruited through several means. First, a relatively long, high intensity presynaptic burst of activity (such as a high-frequency train of stimulation) can induce LTP by releasing glutamate onto the postsynaptic receptor while simultaneously depolarizing the postsynaptic cell through stimulation of the non-NMDA type of glutamate receptors (AMPA) which conducts $\mathrm{Na}^{2+}$. Second, and more physiologically relevant, shorter and less intense levels of presynaptic activity can induce hippocampal LTP if the postsynaptic cell is depolarized via an alternative means such as an input from a second afferent pathway. As alluded above, LTP can be induced without the participation of NMDA receptors, provided that the retanus (or postsynaptic depolarization) is of an intensity to induce a sufficient $\mathrm{Ca}^{2+}$ load via influx through voltage-dependent $\mathrm{Ca}^{2+}$ channels $/ 119,148 /$. Thus, while activation of the NMDA receptor may be critical to these (but not other) forms of LTP, even in these cases it may not be necessary. The consequence of NMDA receptor stimulation, a rise in intracellular $\mathrm{Ca}^{2+}$, appears to be the critical element necessary for initiation of most forms of LTP.

\section{2 $\mathrm{Ca}^{2+}$-dependent biochemical processes underlying potentiation}

A generic model of LTP induction in the hippocampus (excluding CA3 pyramidal cells) is depicted in Figure 5. Since a rise in postsynaptic $\mathrm{Ca}^{2+}$ is presumed necessary for the induction of LTP, much emphasis has been placed on the elucidation of the underlying $\mathrm{Ca}^{2+}$-dependent processes. Several different approaches have been taken to achieve this goal, including the application of inhibitors of $\mathrm{Ca}^{2+}$-dependent enzymes, the direct activation of $\mathrm{Ca}^{2+}$-dependent enzymes in the postsynaptic cells, biochemical assays of enzyme activity and distribution, and most recently, the ablation of genes that encode specific $\mathrm{Ca}^{2+}$-dependent enzymes. In such a complicated system, each of these approaches are subject to interpretative difficulties (see reviews by $185,245 /$ ), but collectively they strongly implicate a role for $\mathrm{Ca}^{2+}$-dependent enzymes in the induction of LTP. For instance, it has been demonstrated that introduction of activated $\mathrm{Ca}^{2+} /$ calmodulin-dependent kinase (CaMK) into the postsynaptic cell induces LTP and blocks LTP induction by afferent stimulation (i.e., acts as a competitive antagonist $/ 216 /$ ), and that peptidergic inhibition of calmodulin blocks LTP induction $/ 170 /$. Moreover, mice deficient in the gene that codes CaMK are similarly deficient in hippocampal LTP as well as the capacity to acquire new (hippocampal dependent) spatial memories $/ 189,247,248 /$.

Though suggestive, any conclusion based on the above observations is complicated by similar experiments that indicate an analogous role for CAMP-dependent kinases $/ 62,108,219 /$ and for PKC $/ 1,172,174,224 /$, as well as other kinases $/ 207,280 /$. Since these kinases contribute in many ways to regulatory functions, signal transduction cascades, and normal synaptic transmission, it cannot be said with certainty that their inhibition does not affect processes that are only indirectly relevant to LTP. In this regard, it is important to note that it has been demonstrated that induction of hippocampal LTP is accompanied by a translocation of PKC from the cytosol to the membrane of postsynaptic cells $/ 6$, $22,142 /$. PKC (among other kinases) is an allosteric enzyme, and in the typical isoforms, its activation is dependent on (and indicated by) its interaction with membrane lipids $205 /$. Similarly, it has been observed that PKA activity increases during the induction phase of LTP /227/. These observations suggest that PKC and/or PKA are activated by stimulation protocols sufficient for the induction of LTP, and are consistent with a specific role for these $\mathrm{Ca}^{2+}$-dependent kinases in this form of facilitation. At present it is not clear whether these kinases act on similar or independent substrates, although it has been suggested that they may play separate roles in the induction and maintenance phases of LTP/131,204/.

\subsection{Stimulus convergence and LTP induction}

Forms of LTP that are normally induced by prolonged stimulation of the NMDA receptor do not necessarily require the convergence of multiple inputs onto a single target cell for induction. In fact, in their first full report on LTP, Bliss and Llomo 138/ demonstrated that high frequency stimulation 


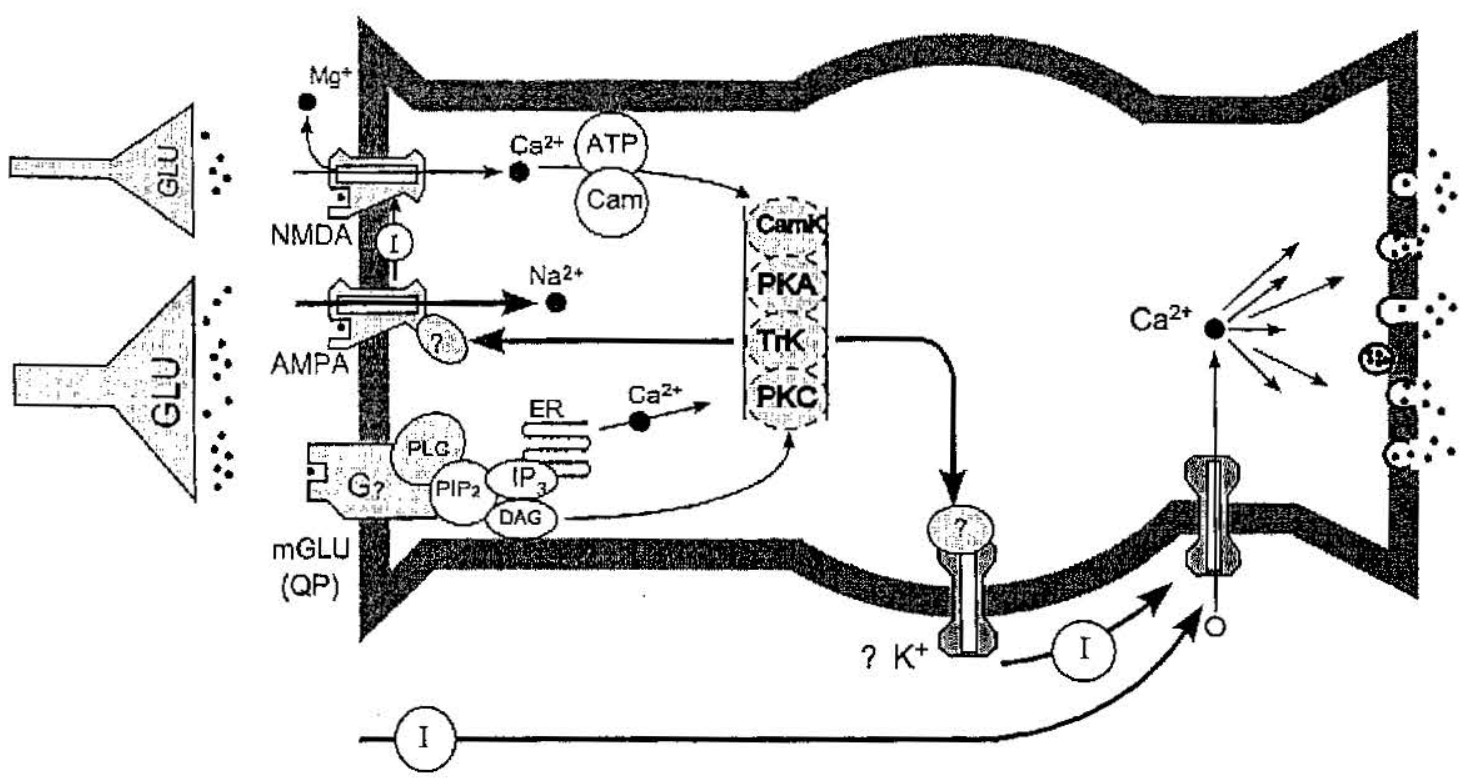

Fig. 5: Molecular constituents of hippocampal long-term potentiation (LTP). Glutamate (GLU) binds to three classes of receptors which tend to be colocalized on these cells. Ionotropic AMPA receptors are directly coupled to a $\mathrm{Na}^{+}$channel which mediates fast synaptic response and induces postsynaptic depolarization via the resultant EPSP. Likewise, the ionotropic NMDA receptor is stimulated directly by glutamate, but will not conduct current unless the postsynaptic membrane is also depolarized, which induces a voltage-dependent expulsion of $\mathrm{Mg}^{2+}$ ions which otherwise clog the channel. When open, the channel conducts a large $\mathrm{Ca}^{2+}$ current. The metabotropic glutamate receptor (mGLU) contributes little to postsynaptic voltage responses but stimulates a PLC transduction cascade which cleaves $\mathrm{PP}_{3}$ and DAG from $\mathrm{PIP}_{2}$, generating a release of $\mathrm{Ca}^{2+}$ from intracellular pools as well as the potential activation of PKC (by DAG and $\mathrm{Ca}^{2-}$ ). At present, the relative contribution of these receptors to LTP is uncertain, and stimulation of either the NMDA or mGLU receptor in isolation can induce LTP, although probably through independent mechanisms. Regardless, LTP induction requires the interaction of $\mathrm{Ca}^{2+}$ (and probably DAG) with several classes of protein kinases, and the activity of at least two of those kinases (PKC and PKA) is increased by the induction protocol. Moreover, although it is well established that the expression of LTP involves an increase in conductance through the AMPA. receptor, other modifications (not depicted) of both pre- and postsynaptic function have been reported to contribute to the potentiation of the EPSP indicative of LTP. Conceptually, associative LTP can be viewed as the sufficient stimulation of any two receptor classes to induce a large rise in intracellular $\mathrm{Ca}^{2+}$ concentration. This can also occur through the weak stimulation of the NMDA receptor combined with postsynaptic depolarization arising from an independent pathway. However, even levels of synaptic transmission sufficient to initiate $\mathrm{Ca}^{2+}$ flux through the NMDA channel may be insufficient under normal conditions to induce LTP in vivo, suggesting a potentially critical role for the generation of interactive second messengers by conjoint stimulation of the $\mathrm{MGLU}$ receptor. Since these receptors are colocalized and may be stimulated by a single input, associative LTP is more representative of the additive effects of an increased level of stimulation, as opposed to the synergistic mechanisms suggested to underlie associative neuronal facilitation in Aplysia and Hermissenda. Still, one way to induce or enhance the induction of LTP, is through the conjoint actions of $\mathrm{Ca}^{2+}$ influx and stimulation of a G-protein-dependent transduction cascades. Such an interaction of these two receptor classes may represent the most common and/or efficient induction mechanism in vivo. In this regard, it should be noted that high levels of intracellular $\mathrm{Ca}^{2+}$ is in itself sufficient to induce a reduced form of facilitation in both Aplysia and Hermissenda, but sufficiently high levels are not likely to occur under physiologically relevant conditions.

of an afferent pathway was in itself sufficient for LTP induction. As described above, this potentiation arises from a combined influx of $\mathrm{Ca}^{2+}$ through $/$ NMDA and voltage-dependent channels, and the resultant activation of $\mathrm{Ca}^{2+}$-dependent kinases.

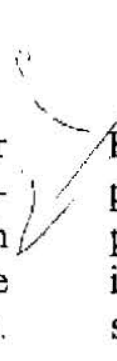

However, the afferent volley necessary to induce potentiation may not commonly occur under physiological conditions, or may be insufficient to induce sustained potentiation $/ 152,168,169 /$. Consequently, it is useful to think of tetanus-induced 
LTP as an extreme version of a mechanism that may be recruited under different conditions in the behaving animal. These conditions may take one of several forms. Commonly, LTP is described as being induced "associatively", a term borrowed from the Pavlovian conditioning literature. When discussing LTP, associativity refers to the observation that roughly contiguous, low intensity stimulation of two pathways, or higher intensity stimulation of convergent weak inputs are sometimes sufficient for the induction of LTP when stimulation of neither pathway alone is sufficient $132,159 /$. In some instances, this associative property may be a reflection of the same underlying mechanism as the strictly $\mathrm{Ca}^{2+}$-dependent form of LTP described above, that is, converging inputs onto a single postsynaptic target may generate a sufficiently large intracellular $\mathrm{Ca}^{2+}$ signal (often through the combined contribution of depolarization-induced $\mathrm{Ca}^{2+}$ influx and activation of the NMDA receptor) to activate postsynaptic kinases. The existence of this associative feature of LTP suggests that LTP may be unlikely to result from normal synaptic transmission, but rather, might be reserved for detection of spatially and temporally contiguous events (i.e., as in associative learning).

Although associative LTP can arise solely as a result of the summation of postsynaptic $\mathrm{Ca}^{2+}$ signals, it may in some instances reflect a mechanism similar to those described above underlying learning in Hermissenda and Aplysia. Regarding this point, it is useful to note that allosteric protein kinases may have varying "degrees" of activity. As described above, for instance, PKC activation by $\mathrm{DAG}$ and $\mathrm{Ca}^{2+}$ is accompanied by a relatively weak association with the neuronal membrane that is enhanced and prolonged by AA /205/. Since DAG and $\mathrm{AA}$ generation occur in response to stimulation of receptor-coupled G-proteins, these cofactors for the activation of PKC might act in combination with NMDA-dependent $\mathrm{Ca}^{2+}$ influx to synergistically activate PKC during associative LTP induction. Numerous studies provide indirect support for such a hypothesis, including the observation that LTP in CAl pyramidal cells can be induced or enhanced by direct stimulation of metabotropic glutamate receptors with the agonist ACPD $/ 43,44 /$, and that ACPDinduced long-lasting potentiation occurs in the absence of the short-term potentiation that normally accompanies tetanus-induced LTP. Moreover, ACPD-induced potentiation occurs in the presence of NMDA receptor antagonists $/ 42,43 /$, and in the presence of antagonists of the metabotropic glutamate receptor; tetanizing stimulation of the afferents to CAl pyramidal cells induces short-term potentiation but no persistent potentiation. These results suggest that although the NMDA receptor is necessary for short-term potentiation and contributes to LTP through the generation of a postsynaptic $\mathrm{Ca}^{2+}$ signal, persistent LTP requires the coactivation of metabotropic glutamate receptors and the resultant generation of a second messenger signal.

Consistent with the proposed role of metabotropic receptors in LTP, it has been demonstrated that a complex of aluminum and fluoride ions $\left(\mathrm{AlF}_{4}{ }^{-}\right)$, which activates $\mathrm{G}$-proteins by simulating the terminal phosphate of GTP, induces LTP in hippocampal slices $/ 218 /$, and that this induction is not dependent on $\mathrm{Ca}^{2+}$ flux through the NMDA receptor activator but does require the presence of $\mathrm{Ca}^{2+}$ in the bathing medium as well as the stimulation of phosphoinositide signaling pathways $/ 48 /$. It should be noted that in the case of $\mathrm{AlF}_{4}{ }_{4}$ and ACPDinduced potentiation, LTP can be induced either through a G-protein mediated release of $\mathrm{Ca}^{2+}$ from intracellular storage pools $136,192 /$ or through the G-protein mediated generation of second messengers which in combination with $\mathrm{Ca}^{2+}$ synergistically activate or prolong the activation of a protein kinase. In the case of ACPD, it is known that it induces a release of $\mathrm{Ca}^{2+}$ from intracellular stores /107/. However, this $\mathrm{Ca}^{2+}$ signal alone is unlikely to be solely responsible for the induction of LTP, in that it is not sufficient to induce transient short-term potentiation. More likely, the phosphoinositide signaling pathway responsible for the stimulation of intracellular $\mathrm{Ca}^{2+}$ pools also generates the release of $\mathrm{Ca}^{2+}$-sensitive second messengers such as DAG, which in turn could activate kinases such as PKC. The possibility that the metabotropic glutamate receptor contributes to the induction of LTP through the activation of PKC has previously been suggested by Collingridge and colleagues (e.g., $141,43 /$ ). The potential role of allosteric activation of protein kinases by $\mathrm{Ca}^{2+}$ and phospholipasederived second messengers in LTP induction was previously proposed by Lester and Bramham / 155/, 
and is consistent with the observation that inhibition of PLA $A_{2}$ effectively blocks LTP induction $/ 178,210 /$. Although the exact contribution of such an allosteric mechanism to LTP induction is unknown, analogous signaling pathways are relatively common /140/ and play a central role in a number of phosphorylation events that may be critical to LTP induction (e.g., /67/).

\subsection{Multiple roles of PKC in LTP}

Although at present it is not entirely clear how the various protein kinases implicated in LTP induction interact to induce or maintain LTP, the role of PKC has been particularly well characterized in recent years and provides a representative framework for considering the contribution of various biochemical cascades to enzyme activity. Initial pharmacological evidence for the role of PKC in LTP induction or maintenance was somewhat perplexing, and contradictory results were often obtained with different inhibitors of the enzyme and ith different modes of drug application. Although Iese discrepancies were often attributed to the lack ispecificity of some inhibitors, they also raised the ossibility that different isoenzymes of $\mathrm{PKC}$, with distinct pharmacological sensitivities, might be activated during various LTP induction protocols, and moreover, might contribute to different stages of L.TP maintenance $/ 23,147 /$.

The various isoforms which comprise the PKC family vary in structure, and these structural variations impart each isoform with the requirement for specific combinations of cofactors for activation 1205/. At present, identified isoforms of PKC can be divided into three groups, described as conventional (cPKC), novel (nPKC) and atypical (aPKC). All the subspecies require phosphatidylserine (PS) for their activation but display differential requirements for lipids and $\mathrm{Ca}^{2+}$. The cPKC family requires $\mathrm{Ca}^{2+}$ and diacylglycerol (DAG) for activation, and activation can be enhanced by cis-unsaturated fatty acids (UFAs; e.g., AA), such that in the presence of UFAs, this group of isoenzymes can be activated at basal levels of $\mathrm{Ca}^{2+} / 244 /$. The nPKC family does not require $\mathrm{Ca}^{2+}$ for activation and different isoforms respond differently to UFAs. Activation of isoforms in the aPKC group is independent of both $\mathrm{Ca}^{2+}$ and $\mathrm{DAG}$, but is uniquely dependent on UFAs
139/. This diversity in the modes of activation reflects the heterogeneity of the structures of these enzymes, and is suggestive of many potential routes of activation during an LTP induction protocol.

Recently, direct measurements of PKC using specific antisera /232/ and assays of enzyme activity using specific PKC substrates /141/ began to elucidate the inconsistencies suggested by earlier work based on the pharmacological manipulation of PKC. In these studies, sustained PKC activity has been observed during the maintenance phase of LTP that persists in the absence of $\mathrm{Ca}^{2++}$ or other PKC activators, suggesting that the enzyme becomes autonomously active during this phase. Moreover, it has been suggested that the proteolytic cleavage of the regulatory domain of one PKC isoform (zeta) could result in a persistently active catalytic subunit. These latter results might explain earlier observations that drugs which inhibit the enzyme at its catalytic domain block the maintenance of LTP whereas regulatory inhibition is typically ineffective at this stage. Consistent with this possibility, it has been reported $/ 212 /$ that the degree of potentiation observed during early maintenance of LTP correlates with an increase in PKCzeta. As noted above, the various isoforms of PKC are stimulated by different combinations and subsets of activators. In total, these results suggest that in addition to its role in LTP induction, various forms of LTP expression and maintenance may result from the combinatorial effects of different converging biochemical pathways. It should be recalled that a similar conclusion was arrived at in our previous descriptions of learning in Hermissenda and Aplysia.

In total, studies directed at the elucidation of the mechanisms underlying associative LTP suggest the possibility that the combined action of $\mathrm{Ca}^{2+}$ and receptor-generated second messengers may serve to induce or prolong the expression of LTP. Although a general class of phenomena referred to as LTP appear to be induced by many different protocols, "associative" LTP may be induced most readily and under physiological conditions if an elevation of intracellular $\mathrm{Ca}^{2+}$ and stimulation of G-proteincoupled receptors co-occur in the same postsynaptic cell. Such an induction protocol may more efficiently activate a single class of protein kinase, or alternatively (and as suggested by several 
studies) may activate protein kinases that are not activated by either signal in isolation. In this regard, LTP is conceptually similar to the forms of activitydependent facilitation described in Aplysia and Hermissenda.

\subsection{Biophysical mechanisms underlying the expression of LTP}

In both Hermissenda and Aplysia, activitydependent facilitation arises in large part from the kinase-induced phosphorylation of ion channel proteins which modulate excitability and/or action potential duration. To this point, we have intentionally avoided any discussion of the substrates for the maintenance of potentiation following stimulation protocols that induce LTP. The expression of LTP reflects both enhanced conductance at specific synaptic terminals that are active during the induction protocol, as well as a more general increase in excitability across the postsynaptic membrane $138 \%$. These two components of LTP are likely to interact and thus may complicate any attempt to assess the biophysical substrates of LTP. Moreover, LTP is measured in a number of ways, including (but not limited to) the amplitude of the postsynaptic population spike, the population EPSP, and EPSPs recorded intracellularly in single postsynaptic cell bodies or axons, all of which may reflect varying combinations of interactive mechanisms. Adding to these concerns, biophysical analysis of single synaptic terminals is technically difficult and has only recently become practical. As a result, a consensus view regarding the biophysical substrates of LTP expression has not emerged. It has been suggested that LTP expression is: 1) an entirely presynaptic phenomenon that results from an increase in the number or quantal content of transmitter vesicles released upon stimulation /255/ (but see $/ 132 /$ ); 2) an entirely postsynaptic phenomenon resulting from an increase in number or kinetics of transmission in postsynaptic AMPA (ionotropic glutamate) receptors $/ 19,160,252 /$, or 3 ) a combination of pre- and postsynaptic mechanisms that contribute to both an increase in transmitter release as well as enhanced receptivity at the postsynaptic terminal /254/ (for review, see /173/).

In addition to specific increases in synaptic efficacy, LTP induction is accompanied by an increase in excitability that is not limited to synaptic regions. This was first demonstrated by Bliss and Llomo $138 /$, who reported that a decrease in the threshold for the elicitation of a spike was observed even when the amplitude of the synaptic response was held constant. In fact, although this widespread increase in excitability always accompanies synaptic enhancement, it can be observed in the complete absence of synaptic enhancement $/ 20,61,262 /$ and is accompanied by a decrease in spike-rate accommodation 139 . These observations are reminiscent of the increases in excitability observed in both Aplysia and Hermissenda, and suggest the possibility that LTP is associated with a decrease in $\mathrm{K}^{+}$ conductance across the postsynaptic membrane, although no direct evidence has been reported (cf. 160). In summary, it appears that the expression of LTP is composed of at least two components, and while the increase in synaptic efficacy may in part reflect a more diffuse increase in excitability, the diffuse increase in excitability can clearly occur independently $/ 262 /$.

At this point, no singular description of the substrates of LTP maintenance has emerged, and we will not attempt to review further the current status of this literature. However, we will assume that LTP requires a transient rise in postsynaptic $\mathrm{Ca}^{2+}$ concentration, a concomitant generation of receptor-coupled second messengers, and a resultant activation of one or a class of protein kinases. Moreover, LTP induction and possibly its maintenance is accompanied by a postsynaptic phosphorylation event that results in increased transmission through AMPA-coupled receptors as well as a more general increase in excitability that may involve the reduction of $\mathrm{K}^{+}$conductances.

\section{UBIQUITOUS MECHANISMS UNDERLYING ACTIVITY-DEPENDENT FACILITATION}

A number of similarities in the cellular mechanisms of learning-related forms of synaptic and/or neuronal facilitation have become apparent. As a heuristic convenience, features of activitydependent facilitation can be categorized into several distinct facets, including the nature of the network interactions necessary for facilitation, the biochemical and molecular events that induce 
facilitation, and the biophysical targets of facilitation. We briefly review the degree to which the examples of facilitation described here are analogous with regard to each of these characteristics.

\subsection{Network interactions underlying activity- dependent facilitation}

Activity-dependent facilitation, as first delineated in Aplysia, is in many respects similar to the mechanisms underlying neuronal plasticity in other models of associative learning (i.e., Hermissenda and some forms of hippocampal LTP). Importantly, in all systems, a transient increase in intracellular $\mathrm{Ca}^{2+}$ in combination with stimulation of G-protein coupled surface receptors results in the synergistic modification of membrane proteins which enhances synaptic efficacy, increases cellular excitability, reduces the threshold for the elicitation of an action potential, or modifies the voltage kinetics of the action potential. Although these various forms of facilitation arise from similar network interactions, he exact nature and locus of the modification pears dependent on the cell type, available second ssenger cascades, and particular substrate teins. Somewhat ironically, one principle that erges from this review is that the network teractions that give rise to memory expression in various systems and between cell types are quite diverse and sometimes even complimentary within a single system. Consequently, the elucidation of a singular mechanism of memory expression at the level of single neurons appears unlikely (see also $151 /$.

While the network interactions underlying induction of facilitation in the systems reviewed here share common features, the different mechanisms of expression have important implications regarding the function of a neural network. For instance, LTP is commonly lauded as a potential memory mechanism because it is "synapse specific" and thus can encode complex yet subtle changes in a neural network that are considered necessary to represent a memory. Likewise, synapse-specific modifications could support a greater potential for plasticity than would modifications that occur more diffusely across a cell body. These supposed features of LTP clearly distinguish it from learning in Hermissenda, for which there is no evidence of synapse specificity, as well as in Aplysia for which there are both cell-wide and synapse specific components of facilitation /65/. However, even in the case of LTP, the plastic modifications that accompany an induction protocol are not limited to synapses and are accompanied by enhanced somatic excitability (see discussion above). Moreover, LTP can spread to synapses in adjacent cells not directly stimulated during the induction protocol $/ 40,240 /$, and unilateral LTP induction can induce bilateral changes in mRNA expression that may alter cell excitability $/ 47,249 /$. Thus, although LTP is often cited as a synapse-specific mechanism, direct evidence indicates that LTP expression involves a more pervasive modulation of cellular excitability. Consequently, it may be premature to assume that memory storage devices will be limited to synapsespecific modifications of neural transmission. It is interesting to note that no direct evidence indicates that memories are encoded exclusively as alterations in synaptic efficacy (cf. /211/), and an explicit feature of some network models is that the modulation of excitability along somatic membranes may be sufficient to encode memories $/ 263 /$.

The form, site, or combination of sites that express the plastic modification associated with memory storage have effects on the function of a neural network that go beyond their implications for synapse specificity. For instance, a decrease in spike elicitation threshold or accommodation that results from the reduction of some classes of $\mathrm{K}^{+}$currents will result in an increase in frequency of postsynaptic potentials but not an increase in their amplitude. However, the reduction of a voltagedependent $\mathrm{K}^{+}$current that opposes an action potential might result in both a decrease in threshold and accommodation (as a result of an increase in membrane resistance) while also prolonging the action potential. In this latter case, both the frequency and amplitude of postsynaptic responses might be enhanced. In contrast, an increase in transmission specific to the synapse, or an increase in postsynaptic receptivity, would result in an increase in amplitude of the postsynaptic response with no increase in the frequency of responses. Functionally, the effect of these plastic modifications will depend on the integration of changes in spike frequency, width, and accommodation, as well as the resultant change in amplitude and frequency 
of potentials in the effector cells. Since some combination of these modifications occurs in each of the systems reviewed here, proposed descriptions of their combined effects in a complex network of cells is in large part conjecture. Even in the invertebrate models in which input and output pathways are reasonably well defined, it is generally conceded that the various "learning networks" that have been proposed should be considered as simplified illustrations $/ 230 /$ as opposed to literal descriptions. Given the number of cells and synapses in a functional network of cells, and the number of permutations of each of the potential sources of plasticity, network variations that account for the expression of a stored memory may prove to be as intractable as some have suggested (e.g., /163, 176/). Likewise, hypothetical neural networks based solely on synaptic efficacy which ignore the dynamics of the cells within the network are most certainly inadequate as heuristic devices.

In total, although the network interactions which underlie the induction of various forms of facilitation share important similarities, the mechanisms which contribute to the expression of that facilitation are more idiosyncratic. This lack of concordance is not surprising given the diversity of second-messenger cascades and protein substrates within the nervous system. It does however complicate our understanding of memory, and in part reflects on our limited understanding of the true nature of memory. It should be recognized that descriptions of memory expression, even in the relatively well defined invertebrate nervous systems considered here, are in fact descriptions of the modification of a behavioral response, and although indicative of memory, are not in themselves descriptive of the psychological process of remembering. (It must be noted that a behavioral change can be indicative of memory, but a memory does not require any associated behavioral change, and a behavioral change in and of itself is not memory /194,222/.) A similar argument could be made in regard to the well delineated cerebellar network believed to subserve acquisition of the classically conditioned nictating membrane response in rabbits $1153,253 /$. Although that network accounts for the generation of the conditioned nictatating membrane response, it is clear that the "memory" of the predictive relationship between the CS and US does not necessarily reside in the cerebellar circuit responsible for the generation of that response $1237 /$. In short, the expression of memory and the psychological process of remembering is complex, and the elucidation of these processes will require a better understanding of the dynamics of functional neural networks.

\subsection{Biochemical and molecular events that underlie facilitation}

In spite of our failure to understand the emergent properties of neural networks that account for memory, a critical network interaction appears to play a central and ubiquitous role in the induction of activity-dependent facilitation. Specifically, in each of the systems that we have described, conjoint pre- and postsynaptic activity either induces or augments neuronal/synaptic facilitation. While the specific biochemical and molecular substrates of this stimulus convergence differ in each system, the dissimilarities are eclipsed by the more general concordance of the three systems. Inherent to each of these systems is the necessity for a transient rise in intracellular $\mathrm{Ca}^{2+}$ in the cell or synapse that expresses the plastic modification. Based on the sufficiency of postsynaptic $\mathrm{Ca}^{2+1}$ to induce a reduced form of facilitation, the modifications in Aplysia sensory neurons, Hermissenda photoreceptors, and hippocampal CAI pyramidal cells or dentate granule cells can be classified into different forms of facilitation. In each case, a strong $\mathrm{Ca}^{2+}$ load in the target cell may be sufficient to induce a reduced form of facilitation even in the absence of any converging input onto that target (an in vitro analog of nonassociative learning). For instance, in Hermissenda, strong depolarization of the B photoreceptor (in the absence of input from the presynaptic hair cells) is sufficient to induce a transient reduction of neuronal $\mathrm{K}^{+}$conductance $/ 12,16$, an increase in neuronal excitability and responsivity to light $/ 102,183 /$, as well as a modification of light-elicited behaviors in the intact animal /102/. Likewise, in Aplysia, high frequency activity and a resultant $\mathrm{Ca}^{2+}$ load in the siphon sensory neuron is sufficient to induce a transient broadening of evoked action potentials /91/ of a magnitude similar to that which results from sensitization training. In the case of 
LTP, the "nonassociative" form of potentiation was described prior to any reports of the associative induction protocol. For instance, a presynaptic volley sufficient in itself to strongly depolarize the postsynaptic target induces LTP $/ 38,165 /$, as does strong depolarization of the target cell independent of presynaptic stimulation $/ 120 /$, and both of these effects are dependent on a rise in postsynaptic intracellular $\mathrm{Ca}^{2+}$. As described above, all of these "nonassociative" forms of facilitation have been attributed to a $\mathrm{Ca}^{2+}$-dependent activation of various protein kinases and a resultant phosphorylation of ion or receptor channels (or their precursors).

Each of the nonassociative forms of facilitation described in the preceding paragraph can be enhanced, prolonged, or the $\mathrm{Ca}^{2+}$ requirement reduced, if the $\mathrm{Ca}^{2+}$ signal coincides with the stimulation of G-protein-coupled receptors, a second ubiquitous feature of these model systems. In the case of both Hermissenda and Aplysia, the enhancement of the $\mathrm{Ca}^{2+}$ signal by contiguous timulation of a G-protein-coupled receptor is ributable to a conceptually similar mechanism. In bysia, stimulation of the tail activates "facilitat7 interneurons that project serotonergic fibers to sensory neurons (see Figure 1). Serotonergic ceptors are coupled to the catalytic subunit of adenylate cyclase via an intermediary G-protein. Binding of the transmitter stimulates the cyclase cAMP and cleaves DAG from PLC, each of which activate protein kinases (PKA and PKC, respectively) that phosphorylate two classes of $\mathrm{K}^{+}$ channels. In a resting sensory neuron, the resultant prolongation and decreased threshold for the elicitation of action potentials tends to be shortlived (e.g., up to $24 \mathrm{~h}$, depending on the stimulation protocol) and the effects are rather modest. However, if the sensory neuron is active at the time of 5-HT binding, the activity is accompanied by an influx of $\mathrm{Ca}^{2+}$ through voltage-dependent channels. This conjoint influx of $\mathrm{Ca}^{2+}$ with the stimulation of the receptor-coupled $\mathrm{G}$-protein potentiates the activity of $\mathrm{CAMP}$ and DAG. The increased activity of CAMP and stimulation of multiple PKC isoforms results in a prolonged and enhanced facilitation of the sensory neuron (see Figure 2).

Unlike in Aplysia, in Hermissenda no facilitation arises as a result of presynaptic stimulation alone. Rather, presynaptic stimulation of vestibular hair cells results in the release of GABA onto the terminal branches of the $B$ cell which in turn increases $\mathrm{K}^{+}$conductance across the $\mathrm{B}$ cell membrane via the stimulation of an intermediary Gprotein. (Any effect of hair cell activity-induced 5$\mathrm{HT}$ binding on $\mathrm{K}^{+}$conductance is comparatively small and cannot be directly observed under physiological conditions, i.e., during costimulation of GABA receptors /229/.) A typical effect of the stimulation of the receptor-coupled G-proteins is the release of $\mathrm{AA}$ from its chemical linkage in the bilayer. When the sensory neuron (B cell) is active, as during light-induced depolarization, the activity is accompanied by a rise in intracellular $\mathrm{Ca}^{2+}$ (arising from both voltage-dependent influx and intracellular release) as well as a cleavage of $\mathrm{PIP} \mathrm{P}_{2}$ into $\mathrm{IP}_{3}$ (augmenting the $\mathrm{Ca}^{2+}$ signal by release from intracellular stores) and DAG. High $\mathrm{Ca}^{2+}$ levels alone may cause a weak and transient reduction of several voltage-sensitive $\mathrm{K}^{+}$channels on the cell membrane; however, $\mathrm{Ca}^{2 \cdot 1}$ in combination with $\mathrm{DAG}$ and $\mathrm{AA}$ serves as a potent activator of PKC. This route of activation, unlike the activation induced by light alone, is presumed to result in the activation of unique PKC isoforms and/or a more prolonged association of the kinase with the neuronal membrane. In the membrane, the phosphorylation of $\mathrm{K}^{+}$ channels results in an increase in action potential amplitude and rate of discharge, as well as a decreased threshold for elicitation (see Figure 4).

It is apparent that in both Hermissenda and Aplysia, activity-dependent facilitation represents an amplification of a molecular process which can be initiated nonassociatively, and that this amplification arises from the synergistic action of G-protein stimulated second messengers and high intracellular $\mathrm{Ca}^{2+}$ levels. Interestingly, in both intact Aplysia and Hermissenda it is the CS that induces activity in the sensory neuron which underlies the rise in intracellular $\mathrm{Ca}^{2+}$. However, in the intact Hermissenda the CS (light) induces a transient facilitation of the B cell, while in Aplysia, it is the binding of transmitter to the sensory neuron (arising from the tail shock US) that induces short-term nonassociative facilitation (but see /91/). This illustrates the arbitrary nature of terms like "CS" and "US" and suggests that neither possess specific cellular properties. Rather, our use of the terms CS and US reflects a convenience based on the laboratory 
paradigm and the parameters of a particular experiment. This same logic has been applied to theoretical accounts of learning in which the terms "CS" and "US" have been suggested to have no inherent meaning (/86,222/; see /182/ and $/ 238 /$ for empirical analogs). Rather than imagine that a cellular process is based on properties of a CS or a US, it may be more instructive to assume that behaviors of the organism indicative of the properties of the CS and US arise from higher-order processes that emerge from the animal's attempt to represent its environment in combination with the specific architecture of its neural network $/ 163,230 /$.

As in both Aplysia and Hermissenda, hippocampal LTP results from a $\mathrm{Ca}^{2+}$-dependent molecular cascade which culminates in the activation of protein kinases and the phosphorylation of cytosolic and/or membrane proteins (see Figure 5). Unlike Hermissenda and Aplysia, bowever, the synaptic facilitation that is indicative of LTP may not require the phosphorylation of $\mathrm{K}^{+}$channel proteins, although at present the mechanism responsible for the increase in somatic excitability that accompanies LTP is unknown. Moreover, unlike the facilitation observed in Aplysia and Hermissenda sensory neurons, it appears that the synaptic facilitation indicative of LTP can be induced in its most robust form homosynaptically, that is, strong afferent stimulation can induce a form of potentiation that is as persistent as the potentiation that might follow an associative LTP protocol. As described above, this conclusion must be qualified, given that a typical induction protocol involves the simultaneous stimulation of both ionotropic (NMDA sensitive) and metabotropic (ACPD sensitive) glutamate receptors. In Aplysia and Hermissenda, ionotropic receptors stimulated by the $\mathrm{CS}$ provide a $\mathrm{Ca}^{2+}$ signal while G-protein coupled receptors stimulated by the US generate the production of second messengers that interact with the $\mathrm{Ca}^{2+}$ signal to activate protein kinases. In the case of LTP, this relationship is less well delineated. Not only has LTP been induced by stimulation of either receptor in isolation, it is not yet clear whether the stimulation of the metabotropic glutamate receptor contributes second messengers which interact with the $\mathrm{Ca}^{2+}$ signal (an associative process), or whether the metabotropic glutamate receptors merely augment the $\mathrm{Ca}^{2+}$ signal (via stimulation of cytosolic storage pools) that arises from stimulation of the NMDA channel. In either case, since both ionotropic and metabotropic receptors can be stimulated by a single afferent signal, even "associative" LTP can be induced without the convergence of independent signals as is required in the other models of activity-dependent facilitation described above. For these reasons, hippocampal LTP, often cited as a neurophysiological model of association formation, may not be well suited to serve such a function. It is clear, however, that levels of activity in single afferent fibers that occur in vivo may be insufficient in many instances to induce LTP. Thus, associative LTP, which $c a n$ arise from the independent stimulation of ionotropic and metabotropic receptors via two convergent pathways, may be better suited for the induction of potentiation in vivo.

\subsection{CONCLUSION AND SUMMARY OF UBIQUITOUS MECHANISMS}

Table 1 lists a number of general characteristics of activity-dependent facilitation, and compares these qualities for the forms of facilitation described in Aplysia, Hermissenda, and hippocampal LTP. As was clear from the above descriptions, mechanistic details vary tremendously between these three models, as they often do between various forms of "LTP". It should be apparent from Table 1 that in spite of this variability, each of the model systems share striking global similarities. The single most ubiquitous feature of each of the molecular cascades is the requirement for a rise in intracellular $\mathrm{Ca}^{2+}$ well above resting levels. Not only is this true of the types of facilitation reviewed here, it is true of many other forms of neuronal and/or symaptic facilitation as well as other neuronal growth processes $/ 113$, 250/. Moreover, in each of the three systems reviewed, the rise in intracellular $\mathrm{Ca}^{2+}$ contributes to the activation of a serine/threonine protein kinase and a resultant phosphorylation of receptor channels or neuronal ion channels.

A second ubiquitous feature which emerges from this comparison is the dependence of these various systems on the conjoint stimulation of G-protein coupled receptors. While ionotropic receptors are better suited for the fast transmission of signals between cells, the dependence on and generation of 
TABLE 1

Common features of activity-dependent facilitation

\begin{tabular}{|l|c|c|c|}
\hline & Aplysia & Hermissenda & LTP \\
\hline postsynaptic $\mathrm{Ca}^{2+}$ required & yes & yes & yes \\
\hline depolarization $\left(\mathrm{Ca}^{2+}\right.$ load) alone sufficient & yes $^{3}$ & yes $^{1}$ & yes $^{1}$ \\
\hline $\begin{array}{l}\text { costimulation of G-protein-coupled receptor enhances } \\
\text { requirement for } \mathrm{Ca}^{2+} \text {-dependent protein kinases }\end{array}$ & yes & yes & yes $^{2}$ \\
\cline { 2 - 4 } & yes $^{3}$ & yes $^{3}$ & yes $^{3}$ \\
\hline PKC & yes $^{4}$ & yes $^{4}$ & yes $^{4}$ \\
\hline PKA & yes $^{4}$ & yes $^{5}$ & yes $^{4}$ \\
\hline CaMK & yes & no & yes $^{5}$ \\
\hline phosphorylation of ion channels & yes & yes & yes $^{4}$ \\
\hline phosphorylation of $\mathrm{K}^{+}$channels & yes & yes & $?$ \\
\hline decrease in spike rate accommodation & yes & yes & yes \\
\hline spike broadening & yes & yes & no \\
\hline excitability increases limited to synapse & no & no & no \\
\hline synapse-specific component & yes & ? & yes \\
\hline site of synaptic change & pre/post(?) & post & pre(?)/post \\
\hline
\end{tabular}

'Sufficient to induce a reduced form of facilitation, the effects of which are relatively transient.

May augment $\mathrm{Ca}^{2+}$ signal rather that acting synergistically as in Hermissenda and Aplysia.

${ }^{3}$ Targets of action vaty in each system. The attenuation of facilitation by a kinase inhibitor is not sufficient to assess a kinase's role in the process. Minimally, it is necessary to demonstrate also that the kinase is activated by the induction protocol. These requirements have been met to varying degrees for PKC, PKA, and CaMK in each of the systems reviewed here.

${ }^{4}$ Activated by induction protocol and inhibition prevents induction of facilitation. Distinct isoforms play specific roles in induction and maintenance of facilitation.

${ }^{5}$ Inhibition prevents some aspect of facilitation; activation by induction of facilitation not adequately demonstrated.

${ }^{6}$ Presynaptic modification is probably sufficient.

'Postsynaptic modification is probably sufficient.

second messenger cascades by metabotropic surface receptors makes them uniquely suited for the integration and amplification of signals. In the learning-related neuronal/synaptic facilitation exhibited by both Aplysia and Hermissenda, G-protein coupled receptors play a crucial role as coincidence detectors, modifying the cellular response to otherwise benign $\mathrm{Ca}^{2+}$ signals. In LTP, it appears likely that metabotropic glutamate receptors may serve a similar function, although their contribution re- quires further elucidation. In total, the convergence of two signals, a rise in intracellular $\mathrm{Ca}^{2+}$ and stimulation of G-protein-coupled surface receptors, serves as a cellular device for contiguity detection. Given the similar role that this mechanism plays in each of the systems reviewed, we conclude that the contiguous occurrence of environmental events is a principal determinant of the cellular modifications underlying learning (see also $/ 182,193,213 /$ ). The common assertion that a "contingent" relationship 
between stimuli is the more critical determinant of learning $/ 221,222 /$ is not supported at this mechanistic level. Rather, the effects of contingency in behaving animals are likely to reflect the expression of an integrative process of the larger nervous system.

We propose that a general class of neuronal facilitation can be described as requiring a postsynaptic $\mathrm{Ca}^{2+}$ rise in conjunction with the stimulation of surface receptor-coupled G-proteins and the resultant activation of allosteric serine/threonine protein kinases. Features of these models which are of only incidental relevance appear to be the class of kinase activated by the facilitation protocol, as well as the site of the neuronal modulation relative to the effector targets. Moreover, although it is often stated that the specificity of memory could be accomplished by confining the necessary $\mathrm{Ca}^{2+}$ rise to dendritic spines $/ 167 /$, such a requirement does not appear necessary for memory storage. First, invertebrate neurons do not contain spines, yet invertebrates clearly acquire and retain memories. In addition, although the facilitation that accompanies learning in Aplysia and LTP does appear to have a synapse-specific component (not yet determined in Hermissenda), each of the models that we have described exhibit excitability increases that are not limited to the synapse. Even more strikingly, a once popular notion that a "learning transmitter" would emerge as a common feature of different model systems (see /59/ for discussion) finds no support. from the comparisons made here; learning in Aplysia is dependent on 5-HT, in Hermissenda GABA and 5-HT may serve similar functions, and in hippocampal LTP (though not necessarily other forms) glutamate is critical. Finally, there is no evidence forthcoming from the review of these model systems which would suggest that the de novo synthesis of new pathways (or even new synapses) is necessary for the establishment of an associative memory. It should be noted that in the case of LTP, some evidence would suggest that functionally "silent" synapses become active during the induction regimen /132/, and in Aplysia, sensitization training may enhance dendritic arborization $128,29 /$. Nevertheless, ample evidence suggests that changes in the flow of current through existing neural pathways may be sufficient for the establishment of a new memory.
We have proposed that increased intracellular $\mathrm{Ca}^{2+}$ and stimulation of second messengers by $\mathrm{G}$ protein coupled surface receptors are two elemental and universal cellular events from which neuronal properties are modified and from which memories emerge. It should be noted that events such as muscle contraction $1220,243 /$, cell development $/ 270 /$ and even some forms of cancer /81/ are mechanistically similar to our description of the elemental storage of memory. The observation that similar cascades serve a number of distinct functions speaks to the universality of processes in cell biology, but also raises a question as to how similar processes are ultimately expressed so differently. This paradox might be resolved by noting the distinct protein substrates expressed in neurons that process information, e.g., multiple classes of $\mathrm{K}^{+}$ channels and AMPA receptors. However, the diversity of substrate proteins in the brain is likely greater than in all other organ systems combined, suggesting that several unique substrates are not solely responsible for the differences in the expression of memory-related neuronal facilitation and these other process. A second and more complete solution to this paradox is similarly weak for its imprecision. It is likely (although empirically intractable) that memory is unique owing to the complexity of the neural network that comprises the brain in combination with (or as a consequence of) the unique substrates contained there. Of particular relevance is the observation that brain cells do not act in unison as do the cells which comprise a muscle; rather, to a very large extent, brain cells can respond independently of one another while still in communication. While the elemental cascades that underlie neuronal/synaptic facilitation may play roles in other processes, the psychological process of memory is an emergent phenomenon. Thus it is critically important to distinguish between the elemental units of memory storage and the psychological perception of remembering. While we are largely ignorant with regard to the latter process, the former process is well described as a product of the synergistic action of an activity-induced rise in intracellular $\mathrm{Ca}^{2+}$ and stimulation of receptorcoupled G-proteins on the serine/threonine protein kinases.

In reviewing the three mechanisms of facilitation described here, one might recognize another appar- 
ent contradiction. In Aplysia sensory cells and possibly in associative LTP, it was suggested that the combined action of intracellular $\mathrm{Ca}^{2+}$ and DAG might be sufficient to induce a persistent phosphorylation of substrate proteins, while the same signals were suggested to induce only a weak and transient phosphorylation of substrates in Hermissenda B cells. This disparity may only be indicative of normal diversities in the expression of PKC isoforms in various cell types based on their respective functions. For instance, the B photoreceptor is somewhat unusual in that PKC activation is presumed to occur during routine signal transduction, i.e., during a light response in which the activated enzyme contributes to the maintenance of light-induced generator potentials (through a transient reduction of $\mathrm{K}^{+}$conductance). Thus the $\mathrm{B}$ cell may employ a unique class of protein phosphatases to reverse this phosphorylation and/or may express isoforms of the enzyme that are uniquely sensitive to this combination of activators. Thus in these cells, AA may be required for the prolonged translocation and activation of $\mathrm{PKC}$, whereas in other cell types it is not. Likewise, it has been stablished in both Aplysia sensory cells as well as a hippocampal neurons that different isoforms of 'KC are stimulated concurrently during a typical acilitation protocol, and these isoforms may contribute differentially to different stages of maintenance $/ 147,251 \%$. It is similarly possible that different isoforms of PKC are activated with and without the contribution of AA in Hermissenda $\mathrm{B}$ cells, and that the AA-dependent isoforms bind more effectively and persistently to the neuronal membrane. No direct evidence in support of this hypothesis is presently available, although preliminary data suggest that multiple isoforms of PKC are present in the B cell /198/, and antibody binding studies in our laboratory have identified three distinct isoforms of PKC in B cell extracts (Muzzio and Matzel, unpublished observations).

Contemporary reviews of the induction of learning-related neuronal facilitation have often concluded that the dissimitarities between various systems were too great to warrant the suggestion of any general model of underlying molecular substrates $151,56 /$. The recent delineation of the molecular constituents of facilitation in Hermissenda and the recognition of a contribution of metabotropic receptors to hippocampal LTP have made possible a more meaningful comparison of several of these systems. In conclusion, although many of the details of these molecular cascades differ, important similarities have begun to emerge, and are likely to provide clues about ubiquitous characteristics of memory formation. Although in the present article we considered only induction mechanisms of shortterm memory storage, the elucidation of long-term maintenance mechanisms is likely to illuminate still greater similarities, particularly in that genetic modifications and substrates are often stimulated by the same molecular cascades responsible for these more transient modifications (e.g., $/ 27,113,250$, 277/). An important future consideration will be the elucidation of the signaling pathways by which genetically programmed modifications of membrane/receptor proteins are directed toward the same substrates that are involved in the expression of short-term facilitation (e.g., $/ 109,162,256 /$ ). Since many types of facilitation appear to utilize some or all of the same modifications to influence both short- and long-term facilitation, the identification of such a feedback mechanism may represent the single most important point of convergence between these different model systems of cellular "memory".

\section{ACKNOWLEDGEMENTS}

This work was supported by the US Public Health Service (NIMH Grants MH48387 and MH 52314), the Charles and Johanna Busch Memorial Fund, and a Hoechst-Celanese Young Faculty Award (all to LDM), and an American Psychological Association Predoctoral Minority Fellowship (to IAM). We thank Chet Gandhi and Tracey Shors for their comments on an earlier version of the manuscript.

\section{REFERENCES}

1. Abeliovich A, Chen C, Goda Y, Silva AJ, Stevens CF, Tonegawa S. Modified hippocampal long-term potentiation in PKC gamma-mutant mice. Cell 1993; 75: 1253-1262.

2. Abrams TW. Activity-dependent presynaptic facilitation: An associative mechanism in Aplysia. Cell Mol Neurobiol 1985; 5: 123-145. 
Kax1 A, Kandel ER. Biochemical studies nyergence during classical conditioning ua1 regulation of adenylate cyclase by L and transmitter. J Neurosci 1991; 11:

li $\mathbf{J}$, Crow T. Differential modulation of dent currents in Hermissenda type B 3 by serotonin. J Neurophysiol 1993; 70:

con DL. Sensory convergence on central s in Hermissenda. J Neurophysiol 1980;

ovinger DM, Colley PA, Linden DJ, A. Translocation of protein kinase $\mathrm{C}$ mediate hippocampal long-term potenti1 9 86; 231: 587-589.

[eyler TJ. Long-term and short-term le $\mathrm{CAl}, \mathrm{CA} 3$, and dentate regions of the Jal slice. Brain Res 1976; 110: 463-480. sensory interactions in the nudibranch ti.ssenda crassicornis. Fed Proc 1974; 33:

Membrane depolarization accumulates ition of an associative behavioral change. $210: 1375-1376$.

Calcium-mediated reduction of ionic iophysical memory trace. Science 1984; 45.

Inderson MJ, Kuzirian AJ, Rogers DF, ollin C, Nelson TJ, Kapetanovic IM, GABA-mediated synaptic interaction visual and vestibular pathways of J Neurochem 1993; 61: 556-566.

arley J, Sakakibara M, Hay B. Voltage1cium and calcium-activated potassium molluscan photoreceptor. Biophys J 1984;

IOrtes GF. Responses of photoreceptors in: J Gen Physiol 1972; 60: 631-649.

Jrossman Y. Long-lasting depolarization larization in eye of Hermissenda. J 1978 ; 41: 1328-1342.

Naito S, Kubota M, Chen C, Bank B, , Gallant P, Rasmussen H. Regulation of $\mathbf{K}^{+}$channels by cytoplasmic and sociated C-kinase. J Neurochem 1988;

Sakakibara M. Calcium activates and photoreceptor soma potassium current. 85; 48: 983-995.

Sakakibara M, Forman R, Harrigan J,

- I, Farley J. Reduction of two voltage-

+ currents mediates retention of a learned 3ehav Neural Biol 1985; 44: 278-300.

Shoukimas JJ, Heldman E. Calciumcrease of a voltage-dependent potassium inys J 1982; 40: 245-250.
19. Ambros-Ingerson J. Xiao P. Larson J, Lynch G. Waveform analysis suggests that LiTP alters the kinetics of synaptic receptor channels. Brain Res 1993; 620: 237-244.

20. Andersen $P$, Sundberg SH, Sveen O, Wigstrom H. Specific long-lasting potentiation of synaptic transmission in hippocampal slices. Nature 1977; 266: 736737.

21. Andrade R, Malenka RC, Nicoll RA. A G protein couples serotonin and $\mathrm{GABA}_{\mathrm{B}}$ receptors to the same channels in hippocampus. Science 1986; 234: 12611265 .

22. Angenstein $F$, Riedel $G$, Reymann $K G$, Staak $S$. Hippocampal long-term potentiation in vivo induces translocation of protein kinase C gamma. NeuroReport 1994; 5: 381-384.

23. Angestein F, Staak S. Receptor-mediated activation of protein kinase $C$ in hippocampal long-term potentiation: facts, problems and implications. Prog Neuropsychopharmacol Biol Psychiatry 1997; 21: 427-454.

24. Annau $Z$, Kamin LJ. The conditioned emotional response as a function of intensity of the US. J Comp Physiol Psychol 1961; 54: 428-432.

25. Auerbach SB, Grover LM, Farley J. Neurochemical and immunocytochemical studies of serotonin in the Hermissenda central nervous system. Brain Res Bull 1989; 22: 353-361.

26. Axelrod J, Burch RM, Jelsema CL. Receptor-mediated activation of phospholipase A2 via GTP-binding proteins: arachidonic acid and its metabolites as second messengers, Trends Neurosci 1988; 11: 117123.

27. Bailey CH, Bartsch D, Kandel ER. Toward a molecular definition of long-term memory storage. Proc Natl Acad Sci USA 1996; 93: 13445-13452.

28. Bailey $\mathrm{CH}$, Chen $\mathrm{M}$. Morphological basis of long-term habituation and sensitization in Aplysia. Science 1983; 220: 91-93.

29. Bailey CH, Kandel ER. Structural changes accompanying memory storage. Ann Rev Physiol 1993; 55: 397-430.

30. Bannerman DM, Good MA, Butcher SP, Ramsay M, Morris RG. Distinct components of spatial learning revealed by prior training and NMDA receptor blockade [see comments]. Nature 1995; 378: 182-186.

31. Bao JX, Kandel ER, Hawkins RD. Involvement of preand postsynaptic mechanisms in posttetanic potentiation at Aplysia synapses. Science 1997; 275: 969-973.

32. Barrionuevo G, Brown TH. Associative long-term potentiation in hippocampal slices. Proc Natl Acad Sci USA $1983 ; 80 ; 7347-7251$.

33. Baxter DA, Byrne JH. Serotonergic modulation of two potassium currents in the pleural sensory neurons of Aplysia. J Neurophysiol 1989; 62: 665-679.

34. Baxter DA, Byrne JH. Differential effects of CAMP and serotonin on membrane current, action-potential 
duration, and excitability in somata of pleural sensory neurons of Aplysia, J Neurophysiol 1990; 64: 978-990.

35. Bernier L, Castellucci VF, Kandel ER, Schwartz JH. Facilitatory transmitter causes a selective and prolonged increase in adenosine $3^{\prime} \cdot 5^{\prime}$-monophosphate in sensory neurons mediating the gill and siphon withdrawal reflex in Aplysia. J Neurosci 1982; 2: 1682-1691.

36. Berridge MJ. Inositol triphosphate and calcium signalling. Nature 1993; 361: 315-325.

37. Bliss TV, Gardner-Medwin AR. Long-Iasting potentiation of synaptic transmission in the dentate area of the unanaesthetized rabbit following stimulation of the perforant path. J Physiol (Lond) 1973; 232: 357-374.

38. Bliss TV, Lomo $\mathrm{T}$. Long-lasting potentiation of synaptic transmission in the dentate area of the anaesthetized rabbif following stimulation of the perforant path. J Physiol (Lond) 1973; 232: 331-356.

39. Bliss TVP, Chavez-Noriega LE, Halliwell JV. Longterm potentiation is associated with an increase in the excitability of pyramidal cells in area $\mathrm{CAl}$ of the hippocampal slice. J Physiol 1987; 390: 260P.

40. Boenholfer T, Staiger V, Aertsen A. Synaptic plasticity in rat hippocanipal cell cultures: Local "Hebbian" conjunction of pre- and postsynaptic stimulation. Proc Natl Acad Sci USA 1989; 86: 8113-8117.

41. Bortolotto ZA, Bashir $\mathrm{Zl}$, Davies $\mathrm{CH}$, Collingridge GL. A nolecular switch activated by metabotropic glutarnate receptors regulates induction of long-term potentiation. Nature 1994; 368: 740-743.

2. Bortolotto ZA, Bashir ZI, Davies CH, Taira T, Kaila $\mathrm{K}$, Collingridge GL. Studies on the role of metabotropic glutamate receptors in long -term potentiation: some methodological considerations. J Neurosci Meth $1995 ; 59: 19-24$.

43. Bortolotto ZA, Collingridge GL. Characterisation of LTP induced by the activation of glutamate metabotropic receptors in area $\mathrm{CAl}$ of the hippocampus. Neuropharmacology 1993; 32: 1-9.

44. Bortolotto ZA, Collingridge GL. On the mechanism of long-term potentiation induced by (1S,3R)-1- aminocyclopentane-1,3-dicarboxylic acid (ACPD) in rat hippocampal slices. Neuropharmaclogy 1995; 34: 1003-1014.

45. Boyle MB, Klein M, Smith SJ, Kandel ER. Serotonin increases intracellular $\mathrm{Ca}^{2+}$ transients in voltageclamped sensory neurons of Aplysia californica. Proc Natl Acad Sci USA 1984; 81: 7642-7646.

46. Braha O, Dale $N$, Hochner M, Klein M, Abrams TW, Kandel ER. Second messengers involved in the two processes of presynaptic facilitation that contribute to sensitization and dishabituation in Aplysia sensory neurons. Proc Natl Acad Sci USA 1990; 87: 20402044.

47. Bramham CR, Southard T, Sarvey JM, Herkenham M, Brady LS. Unilateral LTP triggers bilateral increases in hippocampal neurotrophin and trk receptor mRNA expression in behaving rats: Evidence for interhemispheric communication. J Comp Neurol 1996; 368: $371-382$.

48. Breakwell NA, Publicover SJ. Prolonged enhancement of synaptic transmission in area CA1 of rat hippocampal slices induced by $\mathrm{NaF} / \mathrm{AlCl}_{3}$ does not require NMDA receptor activation but is suppressed by inhibitors of phosphoinositide-mediated signalling pathways, Brain Res 1994; 633: 72-76.

49. Brown AM, Birnbaumer L. Direct $G$ protein gating of ion channels. Am J Physiol 1988; 254: H401-410.

50. Burch RM, Luini $A$, Axelrod J. Phospholipase $A_{2}$ and phospholipase $\mathrm{C}$ are activated by distinct GTP-binding proteins in response to $\alpha_{1}$-adrenergic stimulation in FRTL5 thyroid cells. Proc Natl Acad Sci USA 1986; 83: 7201-7205.

51. Byrne $\mathrm{JH}$. Cellular analysis of associative learning. Physiol Rev 1987; 67: 329-439.

52. Byrne JH, Baxter DA, Buonomano DV, Raymond $\mathrm{J}$. Neuronal and network determinants of simple and higher-order features of associative leaming: experimental and modeling approaches. Cold Spring Harb Symp Quant Biol 1990; 55: 175-186.

53. Byrne JH. Castellucci V, Kandel ER. Receptive fields and response properties of mechanoreceptor neurons innervating siphon skin and mantle shelf. $J$ Newrophysiol 1974; 37; 1041-1064.

54. Byme JH, Kandel ER. Presynaptic facilitation revisited: state and time dependence. J Neurosci 1998; 16: 425-435.

55. Carew TJ, Hawkins RD, Kandel ER. Differential classical conditioning of a defensive withdrawal reflex in Aplysia californica. Science 1983; 219: 397-400.

56. Carew TJ, Sahley CL. Invertebrate learning and memory: from behavior to molecules. Ann Rev Neurosci 1986; 9: 435-487.

57. Carew TJ, Walters ET, Kandel ER. Classical conditioning in a simple withdrawal reflex in Aplysia californica. J Neurosci 1981; 1: 1426-1437.

58. Castellucci V, Kandel ER. Presynaptic facilitation as a mechanism for behavioral sensitization in Aplysia. Science 1976; 194; 1176-1178.

59. Chapouthier G. The search for a biochemistry of memory. Arch Gerontol Geriatr 1989; Suppl 1: 7-19.

60. Chavez-Noriega LE. Bliss TVP, Halliwell JV. Longterm potentiation (LTP) in area CAl of the hippocampus is not associated with changes in calciumdependent afterhyperpolarization (AHP). Neurosci Lett 1987; 29: S97.

61. Chavez-Noriega LE, Halliwell JV, Bliss TV. A decrease in firing threshold observed after induction of the EPSP-spike (E-S) component of long-term potentiation in rat hippocampal slices. Exp Brain Res 1990; 79: $633-64 I$.

62. Chavez-Noriega LE, Stevens CF. Modulation of synaptic efficacy in field CAI of the rat hippocampus by forskolin. Brain Res 1992; 574: 85-92. 
63. Clapham DE. Direct $G$ protein activation of ion channels? Ann Rev Neurosci 1994; 17: 441-464.

64. Clark GA. Hawkins RD, Kandel ER. Activitydependent presynaptic facilitation provides a cellular mechanism for the temporal specificity of classical conditioning in Aplysia. Learn Memory 1994; 1: 243258.

65. Clark GA, Kandel ER. Induction of long-term facilitation in Aplysia sensory neurons by local application of serotonin to remote synapses. Proc Natl Acad Sci USA 1993; 90: 11411-11415.

66. Clark GA, Schuman EM. Snail's tales: Initial comparison of synaptic plasticity underlying learning in Hermissenda and Aplysia. In: Squire LR, Clark GA, eds. Neuropsychology of Memory. New York: Guilford Press, 1992; 588-602.

67. Coffey ET, Herrero I, Sihra TS, Sanchez-Prieto J, Nicholls DG. Glutamate exocytosis and MARCKS phosphorylation are enhanced by a metabotropic glutamate receptor coupled to a protein kinase $C$ synergystically activated by diacylglycerol and arachidonic acid. J Neurochem 1994; 63: 1303-1310.

68. Colebrook E, Lukowiak K. Learning by the Aplysia model system: Lack of correlation between gill and gill motor neurone responses. J Exp Biol 1988; 135: 411429.

69. Collin C, Ikeno H, Harrigan JF, Lederhendler I, Alkon DL. Sequential modification of membrane currents with classical conditioning. Biophys J 1988; 54: 955960.

70. Collingridge GL, Kehl SJ, McLenuan H. Excitatory amino acids in synaptic transmission in the Shaeffercommissural pathway of the rat hippocampus. J Physiol (Lond) 1983; 443: 33-46.

71. Colwill RM, Absher RA, Roberts ML. Context-US learning in Aplysia californica. J Neurosci 1988; 8: 4434-4439.

72. Connor J, Alkon DL. Light- and voltage-dependent increases of calcium ion concentration in molluscan photoreceptors. J Neurophysiol 1984; 51: 745-752.

73. Critz SD, Baxter DA, Byrne JH. Modulatory effects of serotonin, FMRFamide, and myomodulin on the duration of action potentials, excitability, and membrane currents in tail sensory neurons of Aplysia. J Neurophysiol 1991; 66: 1912-1926.

74. Crow T. Cellular and molecular analysis of associative learning and memory in Hermissenda. Trends Neurosci 1988; 11: 136-142.

75. Crow $\mathrm{T}$, Forrester J. Light paired with serotonin in vivo produces both short- and long-term enhancement of generator potentials of identified B-photoreceptors in Hermissenda. J Neurosci 1991; 11: 608-617.

76. Crow T, Forrester J. Down-regulation of protein kinase $\mathrm{C}$ and kinase inhibitors dissociate short- and long-term enhancement produced by one-trial conditioning of Hermissenda. J Neurophysiol 1993; 69: 636-641.
77. Crow $T$, Forrester J, Williams $M$, Waxham $M N$, Neary JT. Down-regulation of protein kinase C blocks 5-HTinduced enhancement in Hermissenda B photoreceptors. Neurosci Lett 1991; 121: 107-110.

78. Crow $T$, Offenbach $N$. Modification of the initiation of locomotion in Hermissenda: behavioral analysis. Brain Res 1983; 271: 301-310.

79. Crow TJ, Alkon DL. Retention of an associative behavioral change in Hermissenda. Science 1978; 201: 1239-1241.

80. Crow TJ, Alkon DL. Associative behavioral modification in Hermissenda: Cellular correlates. Science 1980; 209: 412-414.

81. Davis RJ, Czech MP. Tumor-promoting phorbol diesters cause the phophorylation of epidermal growth factor receptors in normal human fibroblasts at threonine-654. Proc Natl Acad Sci USA 1985; 82: 1974-1978.

82. Dennis MJ. Electrophysiology of the visual system in a nudibranch moilusk. J Neurophys 1967; 30: 14391465.

83. Detwiler PB. Multiple light-evoked conductance changes in the photoreceptors of Hermissenda crassicornis. J Physiol 1976; 256: 691-708.

84. Detwiler PB, Fuortes MGF. Responses of hair cells in the statocyst of Hermissenda. J Physiol 1975; 251: 107-129.

85. Deutsch JA. Spatial learning in mutant mice. Science 1993; 262: 760-761.

86. Dickinson A, Contemporary Animal Learning Theory. Cambridge: Cambridge University Press, 1980.

87. Dutar $P$, Nicoll RA. A physiological role for $G_{A B A}$ receptors in the central nervous system. Nature 1988; 332: $156-158$.

88. Dutar P, Nicoll RA. Pre- and postsynaptic $G_{A B A}$ receptors in the hippocampus have different pharmacological properties. Neuron 1988; 1: 585-591.

89. Eakin RM, Westfall JA, Dennis MJ. Fine structure of the eye of a nudibranch mollusc, Hermissenda crassicornis. J Cell Sci 1967; 2: 349-358.

90. Edmonds B, Klein M, Dale N, Kandel ER. Contribution of two types of calcium channels to synaptic transmission and plasticity. Science 1990; 250; 11421147.

91. Edstrom JP, Lukowiak KD. Frequency-dependent action potential prolongation in Aplysia pleural sensory neurones. Neuroscience 1997; 16: 451-460.

92. Eliot LS, Dudai Y, Kandel ER, Abrams TW. $\mathrm{Ca}^{2+} /$ calmodulin sensitivity may be common to all forms of neural adenylate cyclase. Proc Natl Acad Sci USA 1989; 86: 9564-9586.

93. Exton JH. Signalling through phosphatidylcholine breakdown. J Biol Chem 1990; 265; 1-4.

94. Exton JH. Phosphalidylcholine breakdown and signal transduction. Biochim Biophys Acta 1994; 1212: 2642. 
95. Falk-Vairant $J$, Crow $T$. Intracellular injections of BAPTA block induction of enhancement in Hermissenda type B-photoreceptors. Neurosci Lett 1992; 147: 45-48.

96. Farley J. Contingency learning and causal detection in Hermissenda: I. Behavior. Behav Neurosci 1987; 101: 13-27.

97. Farley J. Associative training results in persistent reductions in a calcium-activated potassium current in Hermissenda type B photoreceptors. Behav Neurosci 1988; 102: 784-802.

98. Farley J, Alkon DL. Associative neural and behavioral change in Hermissenda: consequences of nervous system orientation for light and pairing specificity. J Neurophysiol 1982; 48: 785-807.

99. Farley J, Alkon DL. Cellular mechanisms of learning, memory, and information storage. Ann Rev Psychol 1985; 36: 419-494.

100. Farley J, Alkon DL. In vitro associative conditioning of Hermissenda: cumulative depolarization of type B photoreceptors and short-term associative behavioral changes. J Neurophysiol 1987; 57: 1639-1668.

101. Farley J, Auerbach S. Protein kinase C activation induces conductance changes in Hermissenda photoreceptors like those seen in associative learning. Nature 1986; 319: 220-223.

102. Farley J, Richards WG, Ling LJ, Liman E, Alkon DL. Membrane changes in a single photoreceptor cause associative learning in Hermissenda. Science 1983; 221: 1201-1203.

3. Farley J, Schuman E. Protein kinase C inhibitors prevent induction and continued expression of cell memory in Hermissenda type B photoreceptors. Proc Natl Acad Sci USA 1991; 88: 2016-2020.

104. Farley J, Wu R. Serotonin modulation of Hermissenda type B photoreceptor light responses and ionic currents: implications for mechanisms underlying associative learning. Brain Res Bull 1989; 22: 335351.

105. Fein A, Corson DW. Excitation of Limulus photoreceptors by vanadate and by a hydrolysis-resistant analog of guanosine triphosphate. Science 1981;212: 555-557.

106. Finch EA, Goldin SM. Calcium and inositol 1,4,5triphosphate-induced $\mathrm{Ca}^{2+}$ release. Science 1994; 265 : 813-815.

107. Frenguelli BG, Potier B, Slater NT, Alford S, Collingridge GL. Metabotropic glutamate receptors and calcium signalling in dendrites of hippocampal CA1 neurones. Neurophamacology 1993; 32: 1229 1237.

108. Frey U, Huang YY, Kandel ER. Effects of cAMP simulate a late stage of LTP in hippocampal CA1 neurons. Science 1993; 260: 1661-1664.

109. Frey U, Morris RGM. Synaptic tagging and long-term potentiation. Nature 1997; 385: 533-536.
110. Frysztak RJ, Crow T. Enhancement of type B and A photoreceptor inhibitory synaptic connections in conditioned Hermissenda. J Neurosci 1994; 14: 12451250.

111. Gage PW. Activation and modulation of neuronal $\mathrm{K}$ channels by GABA. Trends Neurosci 1992; 15: 46-51.

112. Ghirardi M. Braha O, Hochner B, Montorolo PG, Kandel ER, Dale NE. The contributions of PKA and PKC to the presynaptic facilitation of evoked and spontaneous transmitter release at depressed and nondepressed synapses in the sensory neurons of Aplysia. Neuron 1992; 9: 479-489.

113. Ghosh A, Greenberg ME, Calcium signaling in neurons: molecular mechanisms and cellular consequences. Science 1995; 268: 239-247.

114. Glanzman DL. The cellular basis of classical conditioning in Aplysia califormica - it's less simple than you think. Trends Neurosci 1995; 18: 30-36.

115. Goh Y, Alkon DL. Sensory, intemeuronal, and motor interactions within Hermissenda visual pathway. J Neurophysiol 1984; 52: 156-169.

116. Goh Y, Lederhendler I, Alkon DL. Input and output changes of an identified neural pathway are correlated with associative learning in Hermissenda. J Neurosci 1985; 5: 536-543.

117. Grover LM, Farley J. Temporal order sensitivity of associative neural and behavioral changes in Hermissenda. Behav Neurosci 1987; 101: 658-675.

118. Grover LM, Farley J Auerbach SB. Serotonin involvement during in vitro conditioning of Hermissenda. Brain Res Bull 1989; 22: 363-372.

119. Grover LM, Teyler TJ. Two components of long-term potentiation induced by different patterns of afferent activation. Nature $1990 ; 347 ; 477-479$.

120. Hanse E, Gustafsson B. TEA elicits two distinct potentiations of synaptic transmission in the CAl region of the hippocampal slice. J Neurosci 1994; 14: 5028-5034.

121. Hargreaves EL, Cain DP, Vanderwolf $\mathrm{CH}$. Leaming and behavioral long-term potentiation: importance of controlling for motor activity. J Neurosci 1990; 10; 1472-1478.

122. Harrigan JF, Alkon DL. Individual variation in associative leaming of the nudibranch mollusc Hermissenda crassicornis. Biol Bull 1985; 168: 222238.

123. Harris EW, Ganong $\mathrm{AH}$, Cotman $\mathrm{CW}$. Long-term potentiation in the hippocampus involves activation of N-methyl-D-aspartate receptors. Brain Res 1984; 323; 132-137.

124. Hawkins RD, Abrams TW, Carew TJ, Kandel E.R. A cellular mechanism of classical conditioning in Aplysia: activity-dependent amplification of presynaptic facilitation. Science 1983; 219: 400-405.

125. Hawkins RD, Carew TJ, Kandel ER. Effects of interstimulus interval and contingency on classical 
conditioning of the Aplysia siphon withdrawal reflex. J Neurosci 1986; 6: 1695-1701.

126. Hawkins RD, Castellucci VF, Kandel ER. Interneurons involved in mediation and modulation of gillwithdrawal reflex in Aplysia. I. Identification and characterization. J Neurophysiol 1981; 45: 304-314.

127. Hawkins RD, Castellucci VF, Kandel ER. Interneurons involved in mediation and modulation of gill-withdrawal reflex in Aplysia. II. Identified neurons produce heterosynaptic facilitation contributing to behavioral sensitization. J Neurophysiol 1981; 45: 315-328.

128. Hawkins RD, Kandel ER, Siegelbaum SA. Leaming to modulate transmitter release: Themes and variations in synaptic plasticity. Ann Rev Neurosci 1993; 16: 625665.

129. Hochner B, Kandel ER. Modulation of a transient $\mathrm{K}^{+}$ current in the pleural sensory neurons of Aplysia by 5HT and cAMP: Implications for spike broadening. Proc Natl Acad Sci USA 1992; 89: 11476-11480.

130. Homayouni $\mathrm{R}$, Byrne $\mathrm{JH}$, Eskin A. Dynamics of protein phosphorylation in sensory neurons of Aplysia. J Neurosci 1995; 15: 429-438.

131. Huang YY, Kandel ER. Recruitment of long-lasting and protein kinase A-dependent long-term potentiation in the CA1 region of hippocampus requires repeated tetanization. Learn Memory 1994; 1: 74-82.

132. Isaac JT, Nicoll RA, Malenka RC. Evidence for silent synapses: Implications for the expression of LTP. Neuron 1995; 15: 427-434.

133. Jaffe D, Johnston D. Induction of long-term potentiation at hippocampal mossy fiber synapses follows a Hebbian rule. J Neurophysiol 1990; 64: 948-960.

134. Johnston D, Williams S, Jaffe D, Gray R. NMDAreceptor-independent long-term potentiation. Ann Rev Plysiol 1992; 54: 489-505.

135. Kandel ER, Klein M, Castellucci VF, Schacher S, Goelet $P$. Some principles emerging from the study of short- and long-term memory. Neurosci Res 1986; 3: 498-520.

136. Kandel ER, Schwartz JH. Molecular biology of learning: modulation of transmitter release. Science 1982; 218: 433-443.

137. Kandel ER, Tauc L. Heterosynaptic facilitation in neurones of the abdominal ganglion of Aplysia depilans. J Physiol 1965; 181: 1-27.

138. Kandel ER, Tauc L. Mechanisms of heterosynaptic facilitation in the giant cell of the abdominal ganglion of Aplysia depilans. J Physiol 1965; 181: 28-47.

139. Khan WA, Blobe GC, Halpern A, Taylor W, Westel WC, Burns D, Loomis C, Hannun YA. Selective regulation of protein kinase $\mathrm{C}$ isoenzymes by oleic acid. J Biol Chem 1993; 268: 5063-5068.

140. Khan WA, Blobe GC, Hannun YA. Arachidonic acid and free fatty acids as second messengers and the role of protein kinase C. Cell Signal 1995; 7; 171-184.

141. Klann E, Chen SJ, Sweatt JD. Mechanism of protein kinase $\mathrm{C}$ activation during the induction and mainten- ance of long-term polentiation probed using a selective peptide substrate. Proc Natl Acad Sci USA 1993; 90: 8310-8313.

142. Klann E, Chen SJ, Sweatt JD. Persistent protein kinase activation in the maintenance phase of lang-term potentiation. J Biol Chem 1991; 266: 24253-24256.

143. Klein $M$. The role of action potential broadening in synaptic facilitation by serotonin at Aplysia soma-soma synapses. Soc Neurosci Abst 1993; 19: 14.1.

144. Klein M, Camardo J, Kandel ER. Serotonin modulates a specific potassium current in the sensory neurons that show presynaptic facilitation in Aplysia. Proc Natl Acad Sci USA; 79: 5713-5717.

145. Klein M, Hochner B Kandel ER. Facilitatory transmitters and CAMP can modulate accomodation as well as transmitter release in Aplysia sensory neurons: evidence for parallel processing in a single cell. Proc Natl Acad Sci USA 1986; 83: 7998.

146. Krasne FB, Glanzman DL. What can we learn from invertebrate learning? Ann Rev Psychol 1995; 46: 585624.

147. Kruger KE, Sossin WS, Sacktor TC, Bergold PJ, Beushhausen S, Schwartz JH. Cloning and characterization of Ca-dependent and Ca-independent PKCs expressed in Aplysia sensory cells. J Neurosci 1991; 11: 2303-2313.

148. Kullmann DM, Perkel DJ, Manabe T, Nicoll RA. Ca ${ }^{2+}$ entry via postsynaptic voltage-sensitive $\mathrm{Ca}^{2+}$ channels can transiently potentiate excitatory synaptic transmission in the hippocampus. Neuron 1992; 9: 11751183.

149. Kupfermann I, Carew TJ, Kandel ER, Local, reflex and central commands controlling gill and siphon movements in Aplysia. J Neurophysiol 1974; 37: 9961019.

150. Kuzirian AM, Alkon DL, Harris LG. An infracilliary network in statocyst hair cells. J Neurocytol 1981; 10: 497-514.

151. Land PW, Crow T. Serotonin immunoreactivity in the circumesophageal nervous system of Hermissenda crassicornis. Neurosci Lett 1985; 62: 199-205.

152. Larson J, Lynch G. Induction of synaptic potentiation in hippocampus by patterned stimulation involves two events. Science1986; 232: 985-988.

153. Lavond DG, Kim JJ, Thompson RF. Mammalian brain substrates of aversive classical conditioning. Ann Rev Psychol 1993; 44: 317-342.

154. Lederhendler II, Gart S, Alkon DL. Classical conditioning of Hermissenda: origin of a new response. J Neurosci 1986; 6: 1325-1331.

155. Lester DS, Braham CR. Persistent, membraneassociated protein kinase C: From model membranes to synaptic long-term potentiation. Cell Signal 1993; 5: 695-708.

156. Lester DS, Collin C, Etchiberrigaray R, Alkon DL. Arachidonic acid and diacylglycerol act synergistically 
to activate protein kinase $\mathrm{C}$ in vitro and in vivo. Biochem Biophys Res Comm 1991; 179: 1522-1528.

157. Leszcuk M, Ghandi C, Muzzio IA, Matzel LD. Modification of action potential kinetics following associative conditioning of Hermissenda contributes to synaptic facilitation of B photoreceptors. Soc Neurosci Abst 1997; 23; 1339.

158. Levy M, Weller A, Susswein AJ. Learned changes in the rate of respiratory pumping in Aplysia fasciata in response to increases and decreases in seawater concentration. Behav Neurosci 1994; 108: 161-170.

159. Levy WB, Steward O. Temporal contiguity requirements for long-term associative potentiation/ depression in the hippocampus. Neuroscience 1983; 8: 791-797.

160. Liao D, Hessler NA, Malinow R. Activation of postsynaptically silent synapses during pairing-induced LTP in CA1 region of hippocanpal slice. Nature 1995; 375: 400-404.

161. Lin XY, Glanzman DL. Hebbian induction of longterm potentiation of Aplysia sensorimotor synapses: partial requirment for activation of an NMDA-related receptor. Proc R Soc Lond [Biol] 1994; 255: 215-221.

162. Lisman J. What does the nucleus know about memories? J NIH Res 1997; 7: 43-46.

163. Lockery SR, Sejnowski TJ. A lower bound on the detectability of nonassociative learning in the local bending reflex of the medicinal leech. Behav Neur Biol 1993; 59: 208-224.

164. Lukowiak $\mathrm{K}$. In vitro classical conditioning of a gill withdrawl reflex in Aplysia: Neural correlates and possible neural mechanisms. I Neurobiol 1986; 17: 83101.

165. Lynch G, Larson J, Kelso S, Barrionuevo G, Schottler $F$. Intracellular injections of EGTA block induction of hippocampal long-term potentiation. Nature 1983; 305: 719-721.

166. Mackey SL, Kandel ER, Hawkins RD. Identified serotonergic neurons LCB1 and RCBl in cerebral ganglion of Aplysia produce presynaptic facilitation of siphon sensory neurons. J Neurosci 1989; 9; 42274235 .

167. Magee IC, Johnston D. A synaptically controlled, associative signal for Hebbian plasticity in hippocampal neurons [see comments]. Science 1997; 275: 209-213.

168. Malenka RC. Postsynaptic factors control the duration of synaptic enhancement in area CA1 of the hippocampus. Neuron 1991; 6: 53-60.

169. Malenka RC. The role of postsynaptic calcium in the induction of long-term potentiation. Mol Neurobiol 1991; 5: 289-295.

170. Malenka RC, Kauer JA, Perkel DJ, Mauk MD, Kelly PT, Nicoll RA, Waxham MN. An essential role for postsynaptic calmodulin and protein kinase activity in long-term potentiation. Nature 1989; 340: 554-557.
171. Malenka RC, Kauer JA, Zucker RS, Nicoll RA. Postsynaptic calcium is sufficient for potentiation of hippocampal synaptic transmission. Science 1988; 242: 81-84.

172. Malenka RC, Madison DV, Nicoll RA. Potentiation of synaptic transmission in the hippocampus by phorbol esters. Nature 1986; 321: 175-177.

173. Malinow R. LTP: desperately seeking resolution. Science 1994; 266: 1195-1196.

174. Malinow R, Schulman $H$, Tsien RW, Inhibition of postsynaptic PKC or CaMKII blocks induction but not expression of LTP. Science $1989 ; 245 ; 862-869$.

175. Manseau F, Sossin WS, Castellucci VF. Long-term changes in excitability induced by protein kinase $\mathrm{C}$ activation in Aplysia sensory neurons. J Neurophysiol 1998; 79: 1210-1218.

176. Marder E. Invertebrate neurobiology. Polymorphic neural networks. Curr Biol 1994 4: 752-754.

177. Martinez JL, Derrick BE. Long-term potentiation and learning. Ann Rev Psychol 1996; 47: 173-203.

178. Massicotte G, Oliver MW, Lynch G, Baudry M. Effect of bromophenacyl bromide, a phospholipase $\mathrm{A}_{2}$ inhibitor, on the induction and maintenance of LTP in hippocampal slices. Brain Res 1990; 537: 49-53.

179. Matzel LD, Alkon DL. GABA-induced potentiation of neuronal excitability occurs during contiguous pairings with intracellular calcium elevation. Brain Res 1992; 554: 77-84.

181. Matzel LD, Collin C, Alkon DL. Biophysical and behavioral correlates of memory storage, degradation, and reactivation. Behav Neurosci 1992; 106: 954-963.

182. Matzel LD, Held FP, Miller RR. Information and expression of simultaneous and backward associations: Implications for contiguity theory. Learn Motiv 1988; 19: 317-344.

183. Matzel LD, Lederhendler II, Alkon DL. Regulation of short-term associative memory by calcium-dependent protein kinase. J Neurosci 1990; 10; 2300-2307.

184. Matzel LD, Muzzio I, Rogers RF. Complex current and voltage responses to baclofen in a molluscan photoreceptor. J Neurophysiol 1995; 74: 506-518.

185. Matzel LD, Rogers RF. Postsynaptic calcium, but not cumulative depolarization, is necessary for the induction of associative plasticity in Hermissenda. J Neurosci 1993; 13: 5029-5040.

186. Matzel LD, Rogers RF, Talk AC. Bidirectional modulation of neuronal potassium currents by the Gprotein activator aluminum fluoride as a function of intracellular calcium concentration. Neuroscience 1995; 74: 1175-1185.

187. Matzel LD, Schreurs B, Alkon DL. Pavlovian conditioning of distinct components of Hermissenda's responses to rotation. Behav Neur Biol 1990; 54: 131145 .

188. Matzel LD, Schreurs B, Lederhendler I, Alkon DL. Acquisiton of conditioned associations in Hermissenda: Additive effects of contiguity and the forward 
interstimulus interval. Behay Neurosci 1990 104; 597606.

189. Mayford M, Bach ME, Huang YY, Wang L, Hawkins $\mathrm{RD}$, Kandel ER. Control of memory formation through regulated expression of a CaMKII transgene. Science 1996; 274: 1678-1683.

190. McEachern JC, Shaw CA. An alternative to the LTP orthodoxy: a plasticity-pathology continuum model. Brain Res Rev 1996; 22: 51-92.

191. McPhie D, Matzel LD, Lester D, Olds J, Kuzirian A, Alkon DL. Cell specificity of molecular changes occurring during associative leaming in Hermissenda. J Neurochem 1993; 60: 646-651.

192. Meissner G. Ryanodine receptor/ $\mathrm{Ca}^{2 \cdot 1}$ release channels and their regulation by endogenous effectors. Ann Rev Physiol 1994; 56: 485-508.

193. Miller RR, Barnet RC. The role of time in elementary associations. Curr Directions Psychol Sci 1993; 2: 106111.

194. Miller RR, Kasprow WJ, Schachtman TR. Retrieval variability: Sources and consequences. Am J Psychol 1986; 99: 145-218.

195. Murphy GG, Glanzman DL. Enhancement of sensorimotor connections by conditioning-related stimulation in Aplysia depends upon postsynaptic $\mathrm{Ca}^{2+}$. Proc Natl Acad Sci USA 1996; 93: 9931-9936.

196. Murphy GG, Glanzman DL. Mediation of classical conditioning in Aplysia californica by long-term potentiation of sensorimotor synapses [see comments]. Science 1997; 278: 467-471.

197. Muzzio I, Ramirez R, Talk AC, Matzel LD. Interactive contributions of intracellular calcium and calciumdependent protein phosphatases to massed-trials training deficits in Hermissenda. Behav Neurosci 1998; in press.

198. Muzzio I, Talk AC, Matzel LD. Incremental translocation of protein kinase $\mathrm{C}$ underlies the acquisition "curve" during in vitro associative conditioning. Behav Neurosci 1997; 111: 739-753.

199. Muzzio IA, Talk AC, Matzel LD. Intracellular calcium and adaptation of voltage responses to light in Hermissenda B photoreceptors. NeuroReport 1998; 9: 1625-1631.

200. Nakamura S, Nishizuka Y. Lipid mediators and protein kinase $\mathrm{C}$ activation for the intracellular signalling network. J Biochern 1994; 115: 1029-1034.

201. Neary JT, Crow T, Alkon DL. Change in a specific phosphoprotein band following associative learning in Hermissenda. Nature 1981; 293; 658-660.

202. Nelson TJ, Collin C, Alkon DL. Isolation of a Gprotein that is modified by learning and reduces potassium currents in Hermissenda. Science 1990; 247: 1479-1483.

203. Nelson TJ, Sanchez-Andres JV, Schreurs BG, Alkon $\mathrm{DL}$. Classical conditioning-induced changes in lowmolecular-weight GTP-binding proteins in rabbit hippocampus. J Neurochem 1991; 57: 2065-2069.
204. Nguyen PV, Kandel ER. A macromolecular synthesisdependent late phase of long-term potentiation requiring CAMP in the medial perforant pathway of rat hippocarnpal slices. J Neurosci 1996; 16; 3189-3198.

205. Nishizuka Y. Intracellular signalling by hydrolysis of phospholipids and activation of protein kinase $\mathrm{C}$. Science 1992; 258: 607-614.

206. Nosten-Bertrand M, Errington ML, Murphy KP, Tokugawa Y, Barboni E, Kozlova E, Michalovich D, Morris RG, Silver J, Stewart CL, Bliss TV, Morris RJ. Normal spatial learning despite regional inhibition of LTP in mice lacking Thy-1. Nature 1996; 379: 826829.

207. O'Dell TJ, Kandel ER, Grant SG. Long-term potentiation in the hippocampus is blocked by tyrosine kinase inhibitors. Nature 1991; 353: 558-560.

208. Ocorr KA, Walters ET, Byrne JH. Associative conditioning analog selectively increases CAMP levels of tail sensory neurons in Aplysia. Proc Natl Acad Sci USA 1985; 82: 2548-2552.

209. Ogita K, Koide H, Kikkawa U, Kishimoto A, Nishizuka $Y$. The heterogeneity of protein kinase $C$ in signal transduction cascade. Adv Second Messenger Phosphoprotein Res 1990; 24: 218-223.

210. Okada D, Yamagishi S, Sugiyama H. Differential effects of phospholipase inhibitors in long-term potentiation in the rat hippocampal mossy fiber synapses and Schaffer/commissural synapses. Neurosci Lett 1989; 100: 141-146.

211. Olds J, Anderson M, McPhie D, Staten L, Alkon DL. Imaging of memory-specific changes in the distribution of protein kinase $\mathrm{C}$ in the hippocampus. Science $1989 ; 245 ; 866-869$.

212. Osten P, Valsamis L, Harris A, Sacktor TC. Protein synthesis-dependent formation of protein kinase Mzeta in long-term potentiation. J Neurosci 1996; 16: 24442451.

213. Papini MR, Bitterman ME. The role of contingency in classical conditioning. Psychol Rey 1990; 97: 396-403.

214. Payne R. Fluoride blocks an inactivation step of transduction in a locust photoreceptor. I Physiol (Lond) 1982; 325: 261-279.

215. Perkins CC. An analysis of the concept of reinforcement. Psychol Rev 1968; 75: 155-172.

216. Pettit DL, Perlman S, Malinow R. Potentiated transmission and prevention of further LTP by increased CaMKII activity in postsynaptic hippocampal slice neurons. Science 1994; 266: 1881-1885.

217. Pinsker H, Kupferman I, Castellucci V, Kandel ER. Habituation and dishabituation of the gill-withdrawal reflex in Aplysia. Science 1970; 167: 1740-1742.

218. Publicover SJ. Brief exposure to the G-protein activator $\mathrm{NaF} / \mathrm{AlCl}_{3}$ induces prolonged enhancement of synaptic transmission in area CAl of rat hippocampal slices. Exp Brain Res 1991; 84: 680-684.

219. Qi M, Zhuo M, Skalhegg BS, Brandon EP, Kandel ER, McKnight GS, Idzerda $\mathrm{RL}$. Impaired hippocampal 
plasticity in mice lacking the Cbetal catalytic subunit of cAMP-dependent protein kinase. Proc Natl Acad Sci USA 1996; 93: 1571-1576.

220. Rasmussen H, Takuwa Y, Park S. Protein kinase C in the regulation of smooth muscle contraction. FASEB J 1987; 1: 177-185.

221. Rescorla RA. Probability of shock in the presence and absence of CS in fear conditioning. J Comp Physiol Psychol 1968; 66: 1-5.

222. Rescorla RA. Behavioral studies of Pavlovian conditioning. Ann Rev Neurosci 1988; 11: 329-352.

223. Rescorla RA. Pavlovian conditioning. It's not what you think it is. Am Psychol 1988; 43: 151-160.

224. Reymann KG, Schulzeck K, Kase H, Matthies H. Phorbol ester-induced hippocampal long-term potentiation is counteracted by inhibitors of protein kinase $\mathrm{C}$. Exp Brain Res 1988; 71: 227-230.

225. Richards WG, Farley J. Motor correlates of phototaxis and associative learning in Hermissenda crassicornis. Brain Res Bull 1987; 19: 175-189.

226. Richards WG, Farley J, Alkon DL. Extinction of associative learning in Hermissenda: behavior and neural correlates. Behay Brain Res 1984; 14: 161-170.

227. Roberson ED, Sweatt JD. Transient activation of cyclic AMP-dependent protein kinase during hippocampal long-term potentiation. J Biol Chem 1996; 271: 30436 30441.

228. Rogers RF, Fass D, Matzel LD. Current, voltage, and pharmacological substrates of a novel GABA receptor in the visual-vestibular system of Hermissenda. Brain Res 1994; 650: 93-106.

29. Rogers RF, Matzel LD. G-protein mediated responses to localized serotonin application in an invertebrate photoreceptor. NeuroReport 1995; 6: 2161-2165.

230. Rogers RF, Matzel LD. Higer-order associative processing in Hermissenda suggests multiple sites of neuronal modulation. Learn Memory 1995; 2: 279 298.

231. Rogers RF, Talk AC, Matzel LD. Trial-spacing effects in Hermissenda suggest contributions of associative and nonassociative cellular mechanisms, Behav Neurosci 1994; 108: 1030-1042.

232. Sacktor TC, Osten $P$, Valsamis $H$, Jiang $X$, Naik MU, Sublette E. Persistent activation of the zeta isoform of protein kinase $\mathrm{C}$ in the maintenance of long-term potentiation. Proc Natl Acad Sci USA 1993; 90; 83428346.

233. Sacktor TC, Schwartz JH. Sensitizing stimuli cause translocation of protein kinase C in Aplysia sensory neurons. Proc Natl Acad Sci USA 1990; 87: 20362039.

234. Sakakibara $M$, Alkon $\mathrm{DL}$, Kouchi $\mathrm{T}$, Inoue $\mathrm{H}$, Yoshioka T. Induction of the photoresponse by the hydrolysis of polyphosphoinositides in the Hermissenda type B photoreceptor. Biochem Biophys Res Comm 1994; 202: 299-306.
235. Salin PA, Malenka RC, Nicoll RA. Cyclic AMP mediates a presynaptic form of LTP at cerebellar parailel fiber synapses. Neuron 1996; 16: 797-803.

236. Saucier D, Cain DP. Spatial learning without NMDA receptor-dependent long-term potentiation [see comments]. Nature 1995; 378: 186-189.

237. Schneiderman N. Response system divergencies in aversive classical conditioning. In: Black AH, Prokasy WF, eds. Classical Conditioning II: Current Research and Theory. New York: Appleton-Century-Crofts, 1972; 341-376.

238. Schreurs BG, Alkon DL. US-US conditioning of the rabbit's nictatating membrane response: Emergence of a conditioned response without alpha conditioning. Psycobiology 1990; 18: 312-320.

239. Schuman EM, Clark GA. Synaptic facilitation at connections of Hermissenda type B photoreceptors. J Neurosci 1994; 14: 1613-1622.

240. Schuman EM, Madison DV. Locally distributed synaptic potentiation in the hippocampus. Science $1994 ; 263: 532-536$.

241. Schwartzkroin P, Wester K. Long-lasting facilitation of a synaptic potential following tetanization in the in vitro hippocampal slice. Brain Res 1975; 89: 107-119.

242. Scoville WB, Milner B. Loss of recent memory after bilateral hippocampal lesions, J Neurol Neurosurg Psychiat 1957; 20: 11-21.

243. Sellers JR, Adelstein RS. Regulation of contractile activity. Enzymes 1987; 18; 381-418.

244. Shinomura T, Asaoka Y, Oka M, Yoshida K, Nishizuka Y. Synergistic activation of diacylglycerol and unsaturated fatty acid for protein kinase $C$ activation. Proc Natl Acad Sci USA 1991;88; 5149. 5153.

245. Shors TJ, Matzel LD. Long-term potentiation: What's learning got to do with it? Behav Brain Sci 1997; 20: $597-655$

246. Shuster MJ, Camardo JS, Siegelbaum SA, Kandel ER. Cyclic AMP-dependent protein kinase closes the serotonin-sensitive $\mathrm{K}^{+}$channels of Aplysia sensory neurones in cell-frce membrane patches. Nature 1985; 313: 392-395.

247. Silva AJ, Paylor R, Wehner JM, Tonegawa S. Impaired spatial learning in calcium-calmodulin kinase II mutant mice. Science 1992; 257: 206-211.

248. Silva AJ, Stevens CF, Tonegawa S, Wang Y. Deficient hippocampal long-term potentiation in calciumcalmodulin kinase $\amalg$ mutant mice. Science 1992; 257: 201-205.

249. Smirnova T, Laroche S, Errington ML, Hicks AA, Bliss TV, Mallet J. Transsynaptic expression of a presynaptic glutamate receptor during hippocampal long-term potentiation. Science 1993; 262: 433-436.

250. Soderling TR, Calcinm-dependent protein kinases in learning and memory. Adv Second Messenger Phosphoprotein Res 1995; 30: 175-189. 
251. Sossin WW, Sacktor TC, Schwartz JH. Persistent activation of protein kinase $\mathrm{C}$ during the development of long-term facilitation in Aplysia. Learn Memory 1994; 1: 153-212.

252. Staubli U, Ambros-Ingerson J, Lynch G. Receptor changes and LTP: an analysis using aniracetam, a drug that reversibly modifies glutamate (AMPA) receptors. Hippocampus 1992; 2: 49-57.

253. Steinmetz JE, Lavond DG, Ivkovich D, Logan CG, Thompson RF. Disnuption of classical eyelid conditioning after cerebellar lesions: darnage to a memory trace system or a simple performance deficit? J Neurosci $1992 ; 12 ; 4403-4426$.

254. Stephane HRO, Malenka RC, Nicoll RA. Bidirectional control of quantal size by synaptic activity in the hippocampus. Science 1996; 271: 1294-1297.

255. Stevens $C F$. Quantal release of neurotransmitter and long-term potentiation. Cell 1993; 72 (Suppl): 55-63.

256. Steward O. mRNA localization in neurons: A multipurpose mechanism? Neuron 1997; 18: 9-12.

257. Sugita S, Goldsmith JR, Baxter DA, Byrne JH. Involvement of protein kinase $\mathrm{C}$ in serotonin-induced spike broadening and synaptic facilitation in sensorimotor connections of Aplysia. J Neurophysiol 1992; 68: 643-651.

258. Susswein AJ, Schwarz M, Feldman E. Learned changes of feeding behavior in Aplysia in response to edible and inedible foods. J Neurosci 1986; 6; 15131527.

259. Sweatt JD, Kandel ER. Persistent and transcriptionally-dependent increase in protein phosphorylation in long-term facilitation of Aplysia sensory neurons. Nature 1989; 339: 51-54.

260. Talk AC, Matzel LD. Calcium influx and release from intracellular stores contribute differentially to in vitro associative conditioning in Hermissenda photoreceptors. Neurobiol Learn Memory 1996; 66: 183-197.

261. Talk AC, Muzzio I, Matzel LD. The role of phosphoinositides in sensory transduction and activitydependent neuronal facilitation in Hermissenda photoreceptors. Brain Res 1997; 751: 196-205.

262. Taube JS, Schwartzkroin PA. Mechanisms of long. term potentiation: EPSP/spike dissociation, intradendritic recordings, and glutamate sensitivity. J Neurosci 1988; 8: 1632-1644.

263. Tesauro G. A plausible neural circuit for classical conditioning without synaptic plasticity. Proc Natl Acad Sci USA 1988; 85: 2830-2833.

264. Tsau Y, Wu JY, Hopp HP, Cohen LB, Schiminovich D, Falk CX. Distributed aspects of the response to siphon touch in Aplysia: spread of stimulus information and cross-correlation analysis. J Neurosci 1994; 14: 4167-4184.
265. Turkkan JS. Classical conditioning: The new hegemony. Behav Brain Sci 1989; 12: 121-179.

266. Walters ET, Byrne JH. Associative conditioning of single sensory neurons suggests a cellular mechanism for learning. Science 1983; 219: 405-408.

267. Walters ET, Carew TJ, Kandel ER. Associative learning in Aplysia californica. Proc Natl Acad Sci USA 1979; 76: 6675-6676.

268. Walters ET, Carew TJ, Kandel ER. Associative learning in Aplysia: evidence for conditioned fear in an invertebrate. Science 1981; 211: 504-506.

269. Wasserman EA, Miller RR. What's elementary about associative learning? Ann Rev Psychol 1997; 48: 573607.

270. Weinstein IB. Protein kinase, phospholipid and control of growth. Nature 1983; 302: 750.

271. Weiss S, Drummond GI. Biochemical properties of adenylate cyclase in the gill of Aplysia californica. Comp Biochem Physiol 1985; 80: 251-255.

272. West A, Barnes E, Alkon DL. Primary changes of voltage responses during retention of associative learning. J Neurophysiol 1982; 48: 1243-1255.

273. Wu JY, Cohen LB, Falk CX. Neuronal activity during different behaviors in Aplysia: a distributed organization? Science 1994; 263: 820-823.

274. Yamamoto $\mathrm{C}$, Chujo $\mathrm{T}$, Long-term potentiation in thin hippocampal sections studied by intracellular and extracellular recordings. Exp Neurol 1978; 58: 242250.

275. Yamoah E, Crow T. Modulation of calcium currents in Hermissenda photoreceptors by 5-HT and GABA. Biophys Soc Abstr 1994; 20: 486.

276. Yanow SK, Manseau F, Hislop J, Castellucci VF, Sossin WS. Biochemical pathways by which serotonin regulates translation in the nervous system of Aplysia. J Neurochem 1998; 70: 572-583.

277. Yin JC, Tully T. CREB and the formation of long-term memory. Curr Opin Neurobiol 1996; 6: 264-268.

278. Yovell Y, Abrams TW. Temporal asymetry in the activation of Aplysia adenylyl cyclase by calcium and transmitter may explain the temporal requirements of conditioning. Proc Natl Acad Sci USA 1992; 89: 65266530.

279. Yovell Y, Kandel ER, Dudai Y, Abrams TW. Biochemical correlates of short-term sensitization in Aplysia: temporal analysis of adenylate cyclase stimulation in a perfused-membrane preparation. Proc Natl Acad Sci USA 1987; 84: 9285-9289.

280. Zhuo M, Hu Y, Schultz C, Kandel ER, Hawkins RD. Role of guanylyl cyclase and cGMP-dependent protein kinase in long-term potentiation. Nature 1994; 368: $635-639$ 